\title{
Data report: seismic structure beneath the north Cascadia drilling transect of IODP Expedition $311^{1}$
}

\author{
M. Scherwath, ${ }^{2}$ M. Riedel, ${ }^{3}$ G.D. Spence,${ }^{4}$ and R.D. Hyndman ${ }^{4}$
}

\section{Chapter contents}

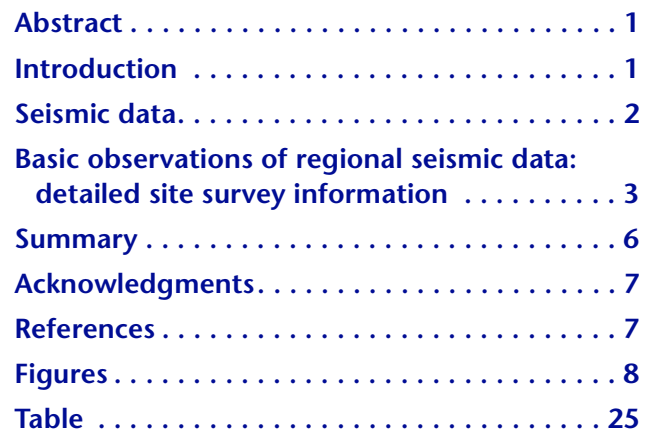

${ }^{1}$ Scherwath, M., Riedel, M., Spence, G.D., and Hyndman, R.D., 2006. Data report: seismic structure beneath the north Cascadia drilling transect of IODP Expedition 311. In Riedel, M., Collett, T.S., Malone, M.J., and the Expedition 311 Scientists. Proc. IODP, 311: Washington, DC (Integrated Ocean Drilling Program Management International, Inc.). doi:10.2204/ iodp.proc.311.110.2006

${ }^{2}$ Leibniz-Institute of Marine Sciences, IFMGEOMAR, Kiel, Germany.

${ }^{3}$ Expedition 311 Scientists' addresses.

Correspondence author: mriedel@eps.mcgill.ca ${ }^{4}$ Earth and Ocean Sciences, University of Victoria, Victoria BC V8W 2Y2, Canada.

\section{Abstract}

Between 1999 and 2004, new seismic data became available for the study of gas hydrates on the northern Cascadia margin. These data consist of multi- and single-channel data with two- and partly three-dimensional subsurface coverage and were acquired and used in support of the proposal for Integrated Ocean Drilling Program (IODP) Expedition 311 carried out in 2005. The working area lies across the continental slope off the coast of central Vancouver Island, British Columbia, Canada, with water depths ranging from $2600 \mathrm{~m}$ in the trench to $500 \mathrm{~m}$ on the upper slope, where it is well above the minimum depth for gas hydrate stability. This paper gives the details of the data acquisition and conventional processing and then focuses on describing the new data at six individual sites along a transect across the gas hydrate zone. Five of the sites were drilled during the Expedition 311. The transect of sites commences at the almost undeformed incoming sediments seaward of the region where gas hydrates are observed; these ocean basin sediments were drilled at a site $40 \mathrm{~km}$ southeast during Ocean Drilling Program (ODP) Leg 146. The transect continues up the continental slope into the area of hydrate stability, with a site on top of the frontal accretionary ridge where normal faulting indicates margin parallel extension; a site in the first slope basin overlying a buried ridge near a reflectivity wipe-out zone; a site adjacent to Site 889 of Leg 146 and therefore acting as a tie hole; the most landward site at the shallowest end of the hydrate stability field; and a cold vent site at one of several blank zones close to a bright spot region in the seismic records.

\section{Introduction}

Gas hydrate fields on the northern Cascadia margin have been comprehensively studied using a multitude of geological, geophysical, and geochemical techniques and data, including reflection seismics. In preparation for Integrated Ocean Drilling Program (IODP) Expedition 311, additional new subsurface imaging data in the form of marine reflection seismics and subbottom profiling with a $3.5 \mathrm{kHz}$ transducer, among other data, were acquired and are presented in this paper. The locations of all site survey data relevant to Expedition 311 are summarized on the map shown in Figure F1. A major objective of this paper is to describe the main features of the subsurface structure at the new drill site 
locations and provide the rational for selecting these sites.

Two major seismic reflection campaigns in 1985 and 1989 resulted in structural images of the northern Cascadia subduction system and helped identify the widespread distribution of gas hydrate in this area (Hyndman et al., 1994). This was followed by drilling Ocean Drilling Program (ODP) Sites 889/890 (Leg 146) into these structures (Westbrook, Carson, Musgrave, et al., 1994). Because Leg 146 comprised only one drill site over undeformed sediments on the oceanic plate (Site 888) and two closely separated sites on the mid-continental slope (Sites 889 and 890), no systematic changes in gas hydrate formation and occurrence along the gas hydrate stability area of the continental shelf could be observed. A new drilling campaign was proposed to address the question about systematic gas hydrate changes that could be related to the amount and duration of fluid flow through the sediments. By drilling a transect of sites from the undeformed sediments off the deformation front up the slope toward the shallowest parts of gas hydrate occurrence, fundamental new insights into the quantification of gas hydrate formation can be addressed. In addition to this, it was proposed to drill into a nearby vent site to expand into unusual high fluid flux areas. A combined geophysical, geochemical, and also microbiological analysis of the drill sites was proposed to study all aspects including the biodiversity of these regions.

From 26 July to 11 August 1999, Cruise PGC9902 of the Canadian research vessel CCGS John P. Tully took place to survey sites for the new IODP proposal. The data acquired comprise seismic reflection data as well as subbottom profiles from a hull-mounted 3.5 $\mathrm{kHz}$ transducer and $12 \mathrm{kHz}$ echo sounding to map the seafloor. For the seismic recording a 40 inch $^{3}$ $(0.65 \mathrm{~L})$ sleeve gun was used. The signals were recorded with the Canadian Oceanographical Acoustic Measurement System (COAMS), a $1140 \mathrm{~m}$ long multichannel seismic (MCS) streamer, as well as by a Teledyne single-channel seismic (SCS) streamer. The profiles were along several main separate corridors and along several closely spaced lines to enable three-dimensional (3-D) data analysis.

Other surveys in the area included Cruises SO111 and SO149 of the German research vessel Sonne to collect multibeam bathymetry (Villinger et al., 1996; Spiess et al., 2001) and three SCS surveys between 1999 and 2004. Two surveys, in 1999 and 2000, were acquired across cold vent sites, again using the 40 inch $^{3}$ sleeve gun and the Teledyne streamer and in a manner for possible 3-D analysis. The last SCS survey took place in 2004, this time with a $40 \mathrm{inch}^{3}$ air gun and the Teledyne streamer to cover alternate drill sites for the proposed IODP drilling.

\section{Seismic data Acquisition}

Cruise PGC9902 used a 40 inch $^{3}(0.65$ L) sleeve gun with a wave shape kit to reduce the bubble ghost. This source was towed at $2 \mathrm{~m}$ depth, $20 \mathrm{~m}$ behind the ship, and fired at a nominal spacing of $20 \mathrm{~m}$. The COAMS streamer has 102 hydrophones at variable, increasing spacings, with offsets ranging from 120 to $1140 \mathrm{~m}$. This MCS streamer consists of five segments, each followed by a depth sensor. Before and after the hydrophones were $100 \mathrm{~m}$ long vibration isolating modules. The COAMS streamer was towed with a $60 \mathrm{~m}$ long cable. The SCS Teledyne array consists of 50 hydrophones along a $25 \mathrm{~m}$ long streamer that was towed $42 \mathrm{~m}$ behind the vessel.

The two-dimensional (2-D) MCS lines of Cruise PGC9902 were shot along four $50 \mathrm{~km}$ long marginperpendicular transects (Fig. F1), two of them continuous (Lines ODP-2 and 3), one split into two parts (Lines ODP-1 and 7), and one split into three segments (Lines ODP-4, 5, and 6). These transects were intersected by five $10 \mathrm{~km}$ long margin-parallel lines (CAS-2, 3, 4, 5A, and 5B). COAMS profiles Inline 27 and Inline 38 were part of a pseudo 3-D component of this survey, in which 40 margin-parallel lines were acquired at a separation of $100 \mathrm{~m}$.

Additional Teledyne SCS lines were shot across alternate or additional drill locations that were not covered with the COAMS data. The cold vent surveys of 1999 and 2000 also collected pseudo-3-D data, this time along lines that were only $25 \mathrm{~m}$ apart. The seismic source was again the 40 inch $^{3}$ sleeve gun. Only the 2004 Teledyne survey used a 40 inch $^{3}$ air gun.

\section{Preprocessing}

The seismic data that we present in this paper stem mainly from the COAMS streamer, and so the data processing focuses on these survey data. The first processing step was to establish the geometry of the seismic recording system. The data were then processed in a conventional manner to produce highresolution structural images.

One key processing step was localization of the hydrophones of the COAMS streamer. Along the streamer, four depth sensors constantly monitor the depth of the streamer, and these revealed that the streamer did not lie flat in the water. A heavy towcable in the front and lead ballast on the last $300 \mathrm{~m}$ of the streamer created down-pull at either end, 
whereas the central section floated high because of the buoyancy of the oil-filled cable. In order to determine the position of each hydrophone, an array element localization (AEL) method developed by Dosso and Riedel (2001) was applied. This method uses the arrival times of the direct wave and the seafloor reflection and matches these with ray-tracing through a known or assumed (in our case measured) water velocity profile over the recorded bathymetry. A linear inversion results in the smoothest streamer shape that fits the measured arrivals. The known hydrophone spacing along the cable and the depth sensor data of the streamer provide a priori information that is also included in the inversion. Slight modification of the software was necessary. The search algorithm to identify the correct reflection segment of the seafloor was improved for this study to allow for highly varying water depth. The result of this inversion is a realistic streamer configuration in the form of offset from the shot and depth below sea surface of each hydrophone.

Initially, this AEL of the streamer was done for every shot along one line. As the shape of the streamer appeared not to vary greatly during the survey, one representative solution of the hydrophone locations was used for the entire survey. In the case of any deviation of the true hydrophone location from the calculated location, subsequent automatic residual static calculations during the data processing were assumed to correct for any time shifts caused by location errors.

\section{Main processing}

After the geometry was assigned for each trace, the data were processed in the manner outlined in Table T1. First, a bandpass filter with smooth ramping was applied, either with a frequency range of $80-250 \mathrm{~Hz}$ for a high-frequency analysis or with a low-frequency range of 30-140 Hz. Spectral analysis of the data showed that the sleeve gun produced signals up to $250 \mathrm{~Hz}$. Lower-frequency data, however, produce clearer images of the bottom-simulating reflector (BSR) as shown by Spence et al. (2000) and Chapman et al. (2002). In order to map both fine structures as well as the BSR, two frequency bands were chosen, and separate images were produced for each frequency band.

Regardless of the frequency range, a predictive deconvolution (Table T1) was applied, which did well in suppressing the strong surface ghost. This was followed by the same bandpass filter as applied before. Thereafter, a spatial linear signal detection (in practice, a velocity filter in the tau-p domain), with subsequent rho filtering to restore the frequency spectrum, was applied.
Velocity analysis was done in a loop with residual static corrections. As mentioned before, our AEL preprocessing solution may not have always taken care of small undulations in the streamer geometry during the entire survey; therefore, automatic alignment of reflectors after normal moveout (NMO) correction produced common midpoint (CMP) gathers that were highly constructive for stacking. Then the NMO correction was removed, and another round of velocity analysis followed. If necessary, a second residual static correction was calculated, which required another velocity analysis.

After stacking the data, despiking with optional automatic gain control (AGC) produced final sections that were then time-migrated either with a Stolt or finite-difference (FD) migration. Stolt migration produced better results with respect to the sediment structure, whereas FD migration was better for amplitude preservation. For clearer display, another AGC was applied if amplitude preservation was not required.

Some of the seismic data shown below come from the Teledyne SCS recording. These data were processed with bandpass filter, deconvolution, and simple migration with an assumed realistic velocity field.

\section{Three-dimensional binning}

Parts of the PGC9902 survey area were covered with seismic lines at $100 \mathrm{~m}$ spacing, enabling a 3-D data analysis. In addition to the processing above, a 3-D grid was created using a bin size of $9.8 \mathrm{~m}$ along the in-line orientation and $100 \mathrm{~m}$ for the cross lines. Because of the large cross-line spacing, 3-D migration of the data produced undesirably strong spatial aliasing; therefore, only 2-D time migration was applied to the data prior to binning.

For the 3-D Teledyne survey data, similar binning considerations as for the 3-D COAMS data were necessary, this time with smaller bins ( $25 \mathrm{~m}$ by $10 \mathrm{~m})$.

\section{$3.5 \mathrm{kHz}$ data}

The $3.5 \mathrm{kHz}$ data required no processing; only the amplitude envelope was used for plotting.

\section{Basic observations of regional seismic data: detailed site survey information \\ Proposed Site CAS-04B}

We present a discussion of structures observed at proposed Site CAS-04B, which was not drilled during 
Expedition 311. This site illuminates the nature of the sediments to be accreted and the initial processes by which they are incorporated into the accretionary wedge. As shown along Line 89-08 (Figs. F2, F3A), the incoming sediments consist of a layer of highly reflective turbidites from $\sim 3.2$ to $4.8 \mathrm{~s}$ two-way traveltime (TWT), or a thickness of $\sim 1.8 \mathrm{~km}$, above a layer of less reflective hemipelagics from $\sim 4.8$ to $\sim 5.5$ $\mathrm{s}$ TWT, or a thickness of $\sim 1.0 \mathrm{~km}$. The total incoming sediment thickness is therefore $2.5-3.0 \mathrm{~km}$, extending from the seafloor at $2.6 \mathrm{~km}$ to the top of ocean crust at $5.0-5.5 \mathrm{~km}$ depth. The lithology of these Cascadia Basin sediments was sampled at Site 888, $\sim 40 \mathrm{~km}$ south of Site CAS-04B. They largely comprise clayey silts with thin beds of fine to coarse sands and gravel and are of late Pleistocene age at the maximum hole depth of $567 \mathrm{~m}$ (Westbrook, Carson, Musgrave, et al., 1994).

The low-frequency seismic Line 85-02, 3 km south of Line 89-08, shows undeformed basin sediments seaward of the large frontal ridge that rises $>800 \mathrm{~m}$ above the deep seafloor. However, Line 89-08 and the coincident higher-frequency MCS Line ODP-7 (Fig. F3), both $\sim 3 \mathrm{~km}$ north of Line 85-02, show that there is significant sediment deformation occurring seaward of this large frontal ridge. Sediment folds peak at shotpoint (SP) 200 and SP 320 along MCS Line ODP-7 (Fig. F3B). For the outer fold at SP 200, the magnitude of folding is significantly smaller above $3.6 \mathrm{~s}$ than below $3.6 \mathrm{~s}$ TWT. This is also associated with sediment onlap from SP 170 to SP 320 above a TWT of $3.6 \mathrm{~s}$, and the decreasing fold magnitude toward the surface indicates deformation synchronous with sedimentation. Both landward- and seaward-dipping thrust faults occur in this structure, and a clear pop-up feature occurs between the two major faults.

Amplitude blanking or weakening occurs at two locations: in the frontal part of the structure around common depth point (CDP) 330, where deformation is greatest, and on the portion of the structure landward of CDP 680 (Fig. F3A). The exact mechanism for blanking is not clear. Presumably it is associated with some type of penetrative deformation, as proposed by Davis and Hyndman (1989) as an explanation for the rapid landward loss of reflectivity for accreted sediments.

The ODP-7 seismic section (Fig. F3B) captures the image of the frontal fold in the process of formation. We note that the nature of this process varies laterally along the margin. Just $2.5 \mathrm{~km}$ south of ODP-7, Line ODP-2 shows little deformation in the incoming sediments seaward of the primary frontal fold, except for incipient folding or faulting. In contrast, along Line ODP-3 just $2.5 \mathrm{~km}$ north of ODP-7, the structure has emerged from the seafloor to form the most recent frontal ridge with a height of almost 200 $\mathrm{m}$ above the deep ocean basin.

\section{Site U1326}

Site U1326 is located at the crest of the first major deformation ridge along the drilling transect and so represents a site with significant uplift. MCS seismic data across the ridge are shown in Figure F4. Velocity analyses of the 1989 MCS data show that the seismic velocities beneath the ridge are nearly the same as velocities in the deep ocean basin at equivalent depths (Yuan et al., 1994). The ridge sediments may therefore be normally compacted. However, velocities in the ocean basin sediments do increase significantly just seaward of the deformation front.

The lower-frequency MCS data (Fig. F4A) clearly image the BSR beneath the crest and on the landward side of the ridge. There is very little reflectivity on the landward side of the ridge, except for very shallow reflectors and a short BSR segment. A BSR is not very evident on the higher-frequency seismic data (Fig. F4B). The weaker BSR at high frequencies indicates that the BSR is not a sharp interface, but rather a velocity gradient zone with a thickness of several meters (Spence et al., 2000; Chapman et al. 2002).

The BSR is well-imaged below the ridge toward the northwest of Line 89-08, for both single-channel and multichannel high-frequency data (Fig. F5). Site U1326 is located $1.4 \mathrm{~km}$ northwest of the intersection of Line CAS-03 with Line 89-08. Along Line CAS-03, sediment reflectors dip in both directions away from the region of Site U1326, so there is a general structural culmination in this region. A series of prominent scarps are present at the seafloor; detailed swath bathymetry shows that the scarps are oriented perpendicular to the margin. The scarps are interpreted as the seafloor expression of normal faults dipping to the northwest (Fig. F5B). The faults apparently accommodate slumping or extension parallel to the margin and perpendicular to the direction of compressive stresses responsible for the uplift of the ridge. Since the faults break the seafloor, fault activity has likely occurred recently.

The recently collected swath bathymetry also shows a major slump feature on the steep seaward side of the ridge, just south of the intersection of Lines CAS03 and 89-08. Drilling on the ridge was originally planned at this intersection point, but with the availability of the new swath bathymetry data, Site U1326 was shifted to the alternate approved location. 


\section{Site U1325}

Site U1325 is situated in a slope basin that developed between two large ridges of accreted sediments (Figs. F6, F7, F8). As seen in the $3.5 \mathrm{kHz}$ data (Fig. F6), the basin floor is covered with a thin layer of transparent Holocene sediments, $\sim 5-7 \mathrm{~m}$ thick. This contrasts with Site U1326 on the frontal ridge, where accreted sediments occur at the seafloor.

Slope basin sediments lie above a buried ridge of accreted sediments, which is located almost in the center of the first slope basin. The slope sediments are highly reflective and continuous. These sediments have only minor deformation in a direction perpendicular to the margin (Fig. F7), although they are somewhat more deformed in a direction parallel to the margin (Fig. F8). The accreted sediments are highly deformed. Their reflectivity and continuity are much reduced relative to the slope basin sediments, and reflection strength is much lower on the high-frequency MCS section (Fig. F7B) relative to the low-frequency section (Fig. F7A). Similarly, the BSR is much less prominent on the high-frequency data, whereas it is very clearly seen on the low-frequency section, mainly within the core of the accreted sediment ridge. A wipe-out zone, or a zone of weakened or chaotic reflectivity, occurs above the crest of the buried ridge; it is particularly evident on high-frequency Line ODP-7 (CDP 7450 in Fig. F7B). The wipe-out zone is also seen in the coincident $3.5 \mathrm{kHz}$ data, although it does not extend quite as high as the seafloor. Site selection was guided by the requirement to avoid this wipe-out zone and the crest of the buried ridge, and so Site U1325 was positioned $\sim 650$ $\mathrm{m}$ from the top of the ridge toward the northeast along Line ODP-7. At this position, the drill hole penetrates a weak segment of BSR (Fig. F7A) near the northeast limit of its occurrence.

\section{Site U1327}

Site U1327 is located along Inline 38 of the pseudo3-D MCS survey conducted in 1999. Situated only $250 \mathrm{~m}$ from the original ODP Hole 889A, the site was selected to provide a tie to the previous drilling so that the previous results could be validated and subsequently extended using the new tools and techniques developed since 1992. In this region, two topographic highs rise $\sim 200 \mathrm{~m}$ above the surrounding seafloor. The topographic highs are composed of accreted sediments, whereas the area between the highs forms a $250 \mathrm{~m}$ deep trough filled with slope basin sediments. The $3.5 \mathrm{kHz}$ data (Fig. F9) along Inline 38 show that the thin transparent layer of Holocene sediments is absent near the drill site, although it is found $\sim 3 \mathrm{~km}$ to the northwest.
The boundary between the accreted and slope sediments is the most prominent feature in the MCS data. The slope sediments are highly reflective and coherent (Fig. F10), and structures within the sediments indicate that deformation and uplift in the region likely occurred during the period that the slope basin sediments were deposited. At Site 889, the uppermost sediments from the seafloor to 87 meters below seafloor (mbsf) comprise mostly clayey silts and silty clays with interbedded thin sand layers (Westbrook, Carson, Musgrave, et al., 1994). With an age from the Holocene to $\sim 450 \mathrm{ka}$, this unit is interpreted to represent little-deformed slope basin turbidites and pelagics. The lower units, which are seismically incoherent (Fig. F10), mainly consist of clayey silt with a low abundance of sand layers. They are pervasively fractured and are interpreted as typical abyssal plain sediments that were heavily deformed during the accretion process.

The drill sites were positioned so that they intersect a strong BSR. The BSR is well developed in this region, as it is in most accreted sediment sections. Reflection coefficients for the BSR were calculated by comparison to amplitudes for the seafloor reflection, which were scaled to a reflection coefficient using the seafloor primary-to-bubble ratio (Warner, 1990). At Site U1327, the BSR reflection coefficient is $~ 0.11$ (Fig. F11A). To the south in the slope basin, the BSR reflection strength reaches a value of $\sim 0.24$ in a crescent-shaped bright spot. The BSR bright spot follows a trough in the boundary surface between the slope sediment and the accreted sediments, as mapped from the pseudo-3-D MCS lines (Fig. F11B). This suggests a structural or tectonic control for the accumulation of gas and/or hydrate within the trough.

\section{Site U1329}

As the most landward of the sites in the transect, Site U1329 represents the end-member of gas hydrate formation in an accretionary prism. Near Site U1329, the BSR can be identified as far upslope as CDP 6400 on MCS Line ODP-1 (Fig. F12B). The BSR is also clearly imaged on SCS data collected in 2004 in the northwest-southeast direction parallel to the shelf edge (Fig. F13). On the lower-frequency MCS Line 89-08 (Fig. F12A), the BSR cannot be clearly identified at the drill site, unlike the confident identification on Line ODP-7. Line 89-08, however, shows the more landward structures clearly: strong, near flatlying sediment reflectors beneath the outer continental shelf (northeast of CDP 3800) increase in dip seaward and become subparallel to the seafloor beneath the steep continental slope.

Near the base of the steep slope section just seaward of Site U1329 (CDP 5600-6000 on Line ODP-1 in Fig. 
F12B), the seafloor is discontinuous and highly disrupted. This probably corresponds to a region of slump accumulation produced by failure along the steep slope. On the $3.5 \mathrm{kHz}$ data (Fig. F14), the irregular reflectivity at the seafloor contrasts strongly with the normal sedimentation patterns just seaward, where the $5 \mathrm{~m}$ thick transparent layer of Holocene sediments drapes over older sediments. Although Site U1329 is located just upslope of this disrupted zone, the site was probably swept by the slumping sediments and the thin transparent layer was removed.

\section{Site U1328}

Site U1328 is located within a cold vent, referred to as Bullseye vent, which is part of a larger cold vent field, $\sim 4 \mathrm{~km} \times 2 \mathrm{~km}$ in dimension. Vents are identified by the presence of subvertical zones of reduced seismic amplitudes (Figs. F15, F16, F17). These blank zones have been observed over a frequency range from $20 \mathrm{~Hz}$ to $4 \mathrm{kHz}$, and the degree of blanking increases with seismic frequency (Riedel et al., 2002). On the $3.5 \mathrm{kHz}$ data (Fig. F15), the blank zones are seen to extend upward to near the seafloor; at Bullseye vent, a seafloor mound, $\sim 6 \mathrm{~m}$ in height, is also observed. The blank zones range from $80 \mathrm{~m}$ to several hundred meters in diameter and are typically elongated in the east-west direction. They are associated with near-surface faults and are bound by highamplitude rims, which in the case of Bullseye appears as a circular feature $\sim 500 \mathrm{~m}$ in diameter (see Fig. F11 in Riedel et al., this volume). The rims are artifacts of seismic diffractions that occur at the edges of the blank zones and enhance regular reflectivity by constructive interference (Riedel, 2001).

The blank zones extend through the entire sediment column to about BSR depth. As discussed in Riedel et al. (this volume), there is no evidence for large velocity anomalies within the bank zone. There is no significant velocity pull-up or pull-down and no anomalous velocities from semblance analyses or tomographic inversions (Zykov and Chapman, 2005). Although the BSR in the area of the cold vent is generally weak, sediment reflections are greatly enhanced above and below the BSR to the south and west of Site U1328 (Fig. F16). This feature forms a seismic bright spot for the BSR, as discussed above and shown in Figure F11A. With reflection coefficients as high as 0.3 , the high amplitudes indicate either the existence of high concentrations of free gas below the BSR or high gas hydrate concentrations above the BSR. For safety reasons, Site U1328 was positioned outside of the bright spot but as close as possible to it.
Reflection coefficients for the seafloor show a strong correlation with the location of seismic blanking for Bullseye vent. As seen in Figure F17A, the seafloor reflection coefficients are $\sim 0.1$ in the circular portion of the blanking zone, which is identified in a time slice of instantaneous amplitude at a depth of 1.752 s (Fig. F17B). Reflectivity within Bullseye vent is less than half of that outside the vent. Presumably, the cause of the reduced reflectivity is produced by reduced near-surface velocities or densities associated with gas released into the sediments from the hydrate cap. Physical property measurements on piston cores, however, show no reduced velocity or density for sediments inside the vent relative to those outside the vent (Riedel et al., 2006).

Within Bullseye vent, a shallow dome-shaped reflector is observed at $\sim 6-11 \mathrm{mbsf}$ (Fig. F17B, F17C). Massive gas hydrate was recovered in piston cores at a depth as shallow as 0.5 mbsf in the center of the vent and dome reflector (Fig. F17B), which supports the interpretation that the reflector represents the cap of a layer of massive hydrate. The thickness of this hydrate layer is not known from the seismic data. Site U1328 was positioned along MCS Inline 27 (Fig. F16A) so that it intersects the hydrate cap reflector near its minimum depth of $6 \mathrm{~m}$.

\section{Summary}

New seismic data from the northern Cascadia margin were acquired from 1999 to 2004 in support of an IODP proposal that resulted in drilling Expedition 311 in 2005. The aim was to study the quantification and systematic changes of gas hydrate formation through a series of sites within the gas hydrate stability field up the continental slope.

The data comprise sleeve and air gun data recorded either on the $1140 \mathrm{~m}$ long COAMS MCS streamer or on the Teledyne single-channel system. Data processing of the COAMS data included localization of the hydrophone depths and offsets because of the strong curvature of the streamer and an otherwise conventional processing scheme. The Teledyne data processing was similarly simple without localization and offset-dependent processing steps. Some areas were covered with densely spaced seismic lines, thus enabling 3-D binning and data analysis.

Our data description focused on six sites, from the trench into and through the gas hydrate stability field up the continental slope. The first site, CAS04B, lies just off the deformation front outside the hydrate stability field, where the hardly deformed sediments are about to be accreted. Equivalent sediments were drilled already during Leg 146, whereas the remaining sites were drilled during Expedition 
311. Site U1326 is located on the frontal ridge where a BSR indicates gas hydrates; the ridge area shows presumably normal fault structures, identified by scarps on the seafloor, with extension parallel to the margin. In the slope basin landward of the seafloor ridge, Site U1325 overlies a buried ridge; adjacent to the drill site is a reflectivity wipe-out zone, and the BSR appears weak. To the northeast, Site U1327 is located between two topographic highs over a strong BSR and acts as a tie hole, as with Site 889. The most landward or end-member site of the transect through the gas hydrate stability field is Site U1329, located over a weak BSR on a steep portion of the slope that is near slumping. Finally, Site U1328 is located at a prominent cold vent, identified in the seismic data as one of several blank zones, but adjacent to a bright spot region where sediment reflectors just above and below the BSR are very strong.

\section{Acknowledgments}

The authors want to express many thanks to Bob MacDonald and Ivan Frydecky for their expertise and support during data acquisition. Special thanks go to the crew of the CCGS John P. Tully and their enthusiastic support during the cruises. We also would like to thank Seismic Micro Technology for donating the 3-D interpretation software package, "The Kingdom Suite," to the University of Victoria. N.R. Chapman and S.E. Dosso made significant contributions to the COAMS equipment. Hydrate research at the University of Victoria has been supported for many years through grants from the Natural Sciences Engineering Research Council to G.D. Spence and R.D. Hyndman, and who financed M. Scherwath during his PDF at the University of Victoria.

\section{References}

Chapman, N.R., Gettrust, J., Walia, R., Hannay, D., Spence, G.D., Wood, W., and Hyndman, R.D., 2002. High-resolution, deep-towed, multichannel seismic survey of deep-sea gas hydrates off western Canada. Geophysics, 67(4):1038-1047. doi:10.1190/1.1500364

Davis, E.E., and Hyndman, R.D., 1989. Accretion and recent deformation of sediments along the northern Cascadia subduction zone. Geol. Soc. Am. Bull., 101(11):1465-1480. doi:10.1130/0016-

7606(1989)101<1465:AARDOS>2.3.CO;2
Dosso, S.E., and Riedel, M., 2001. Array element localization for towed marine seismic surveys. J. Acoust. Soc. Am., 111(2):955-966. doi:10.1121/1.1382618

Hyndman, R.D., Spence, G.D., Yuan, T., and Davis, E.E., 1994. Regional geophysics and structural framework of the Vancouver Island margin accretionary prism. In Westbrook, G.K., Carson, B., Musgrave, R.J., et al., Proc. ODP, Init. Repts., 146 (Pt. 1): College Station, TX (Ocean Drilling Program), 399-419.

Riedel, M., 2001. 3D seismic investigations of northern Cascadia marine gas hydrates [Ph.D. dissert.]. Univ. Victoria, Canada.

Riedel, M., Hyndman, R.D., Spence, G.D., and Chapman, N.R., 2002. Seismic investigations of a vent field associated with gas hydrates, offshore Vancouver Island. $J$. Geophys. Res., [Solid Earth], 107(B9):2200. doi:10.1029/ 2001JB000269

Riedel, M., Novosel, I., Spence, G.D., Hyndman, R.D., Chapman, N.R., and Lewis, T., 2006. Geophysical and geochemical signatures associated with gas hydraterelated venting in the northern Cascadia margin. Geol. Soc. Am. Bull., 118:23-38. doi:10.1130/B25720.1

Spence, G.D. Hyndman, R.D., Chapman, N.R., Riedel, M., Edwards, N., and Yuan, J., 2000. Cascadia margin, northeast Pacific Ocean: hydrate distribution from geophysical investigations. In Max, M.D. (Ed.), Natural Gas Hydrate in Ocean and Permafrost Environments: New York (Kluwer Academic Publisher).

Spiess, V., and Cruise Participants, 2001. Report and preliminary results of R/V Sonne cruise S0149, Victoria-Victoria, 16.8-16.9.2000. Ber., Fachbereich Geowiss., Univ. Bremen, 179.

Villinger, H., and Cruise Participants, 1996. Fahrtbericht SO111, Victoria-Victoria, 20.8.-16.9.1996. Ber., Fachbereich Geowiss., Univ. Bremen, 97.

Warner, M., 1990. Absolute reflection coefficients from deep seismic reflections. Tectonophysics, 173:15-23. doi:10.1016/0040-1951(90)90199-I

Westbrook, G.K., Carson, B., Musgrave, R.J., et al., 1994. Proc. ODP, Init. Repts., 146 (Pt. 1): College Station, TX (Ocean Drilling Program).

Yuan, T., Spence, G.D., and Hyndman, R.D., 1994. Seismic velocities and inferred porosities in the accretionary wedge sediments at the Cascadia margin. J. Geophys. Res., 99(B3):4413-4427. doi:10.1029/93JB03203

Zykov, M., and Chapman, R.N., 2005. Structure of the Bullseye blank zone in northern Cascadia: results of amplitude and velocity studies using OBS data. Eos, Trans. Am. Geophys. Union, 86(52)(Suppl.), OS-42A-01. (Abstract)

Publication: 28 October 2006 MS 311-110 
Figure F1. Site survey seismic data on the northern Cascadia margin relevant to Expedition 311. Overview Line 89-08, shown in Figure F2, is shown in red. Axes are universal transverse Mercator projection easting and northing coordinates using the WGS-84 reference.

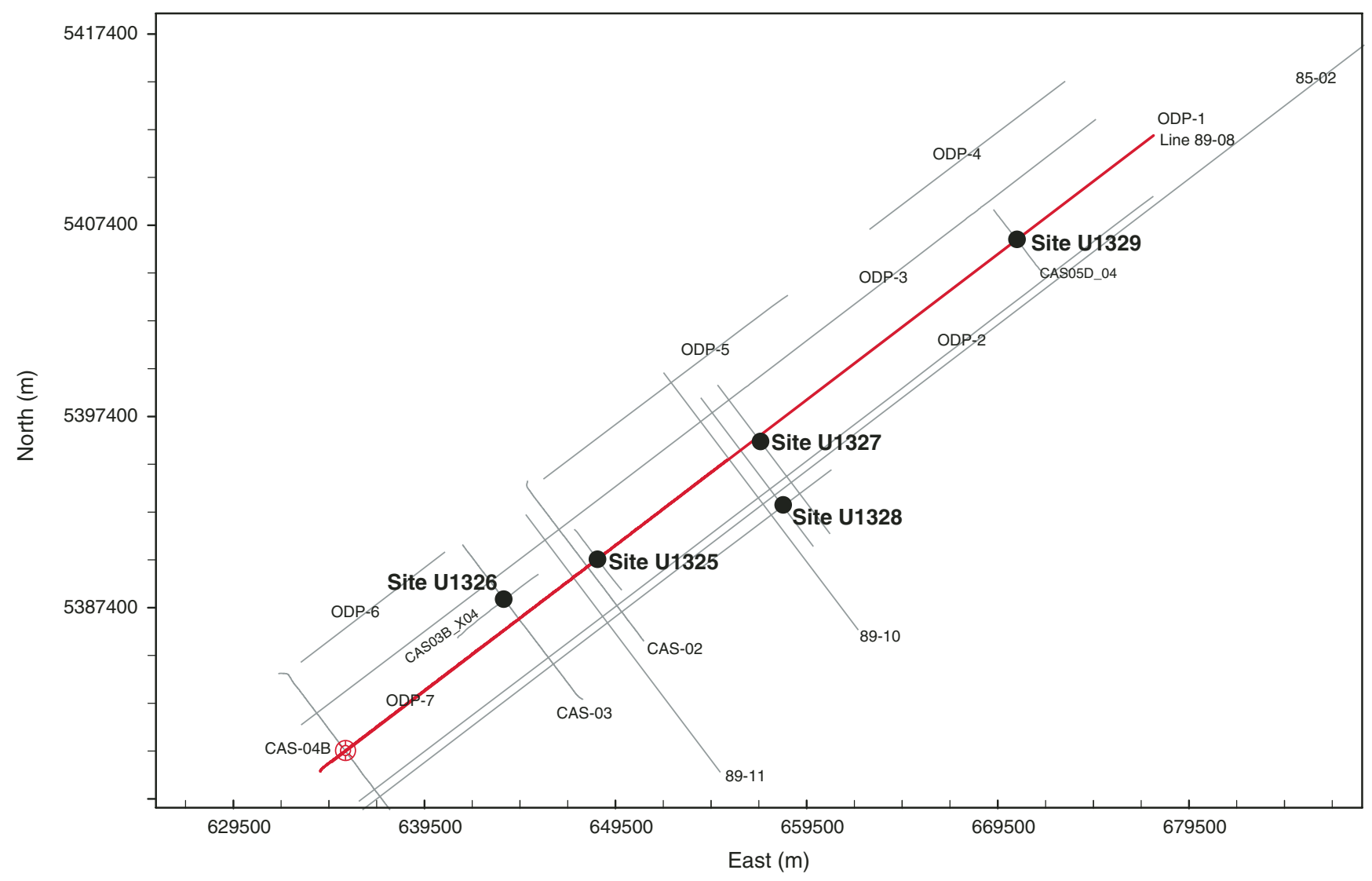


Figure F2. Line 89-08 showing the seismic structure along the transect of drill sites from west of the deformation front into the gas hydrate stability field of the continental slope. BSR = bottom-simulating reflector.

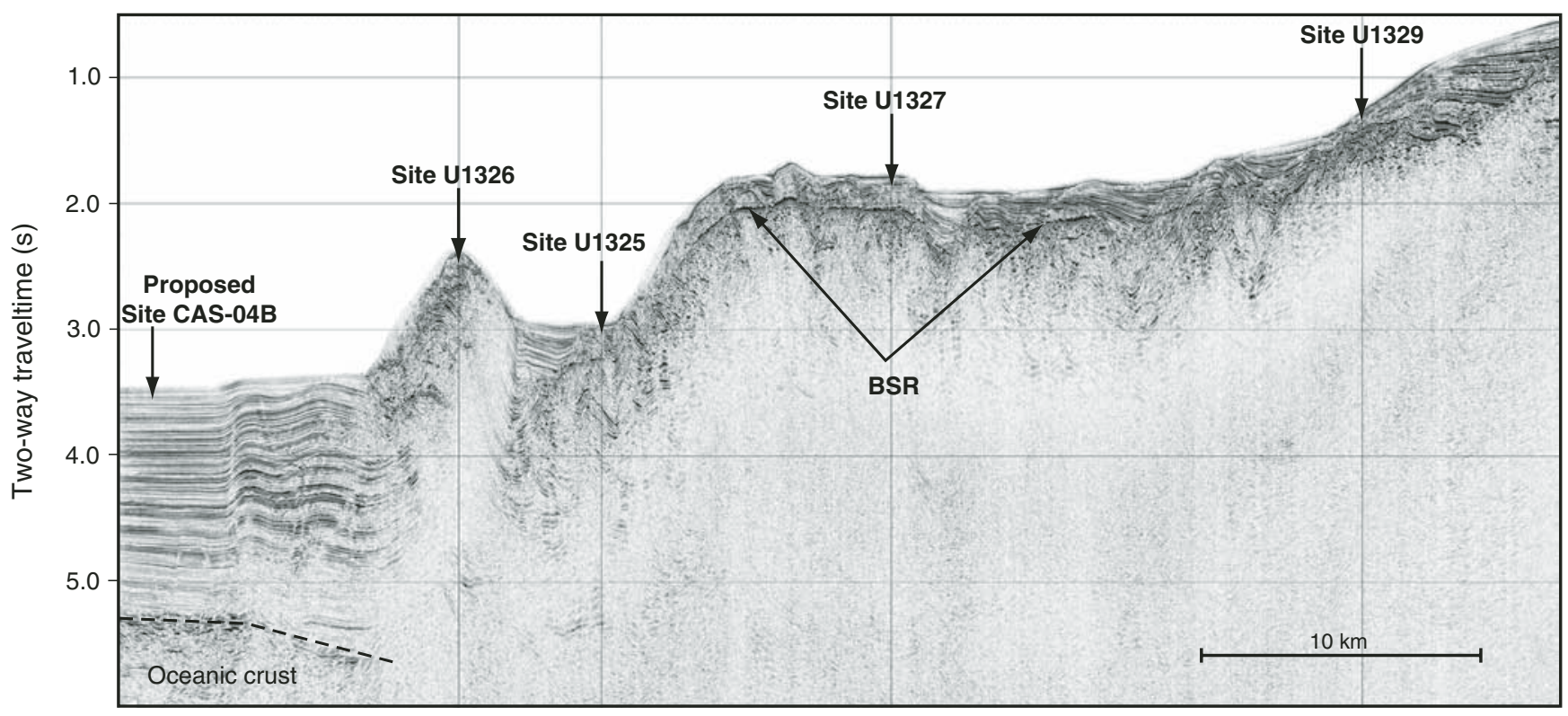


Figure F3. (A) Section of low-frequency MCS Line 89-08 over proposed Site CAS-04B, showing upper reflective turbidites and low-resistivity lower hemipelagic zone of the incoming turbidite sediment section west of the deformation front, and (B) coincident section of high-frequency MCS Line ODP-07 (COAMS data). The dashed lines identify faults that define a pop-up feature. $\mathrm{CPD}=$ common depth point, V.E. = vertical exaggeration.

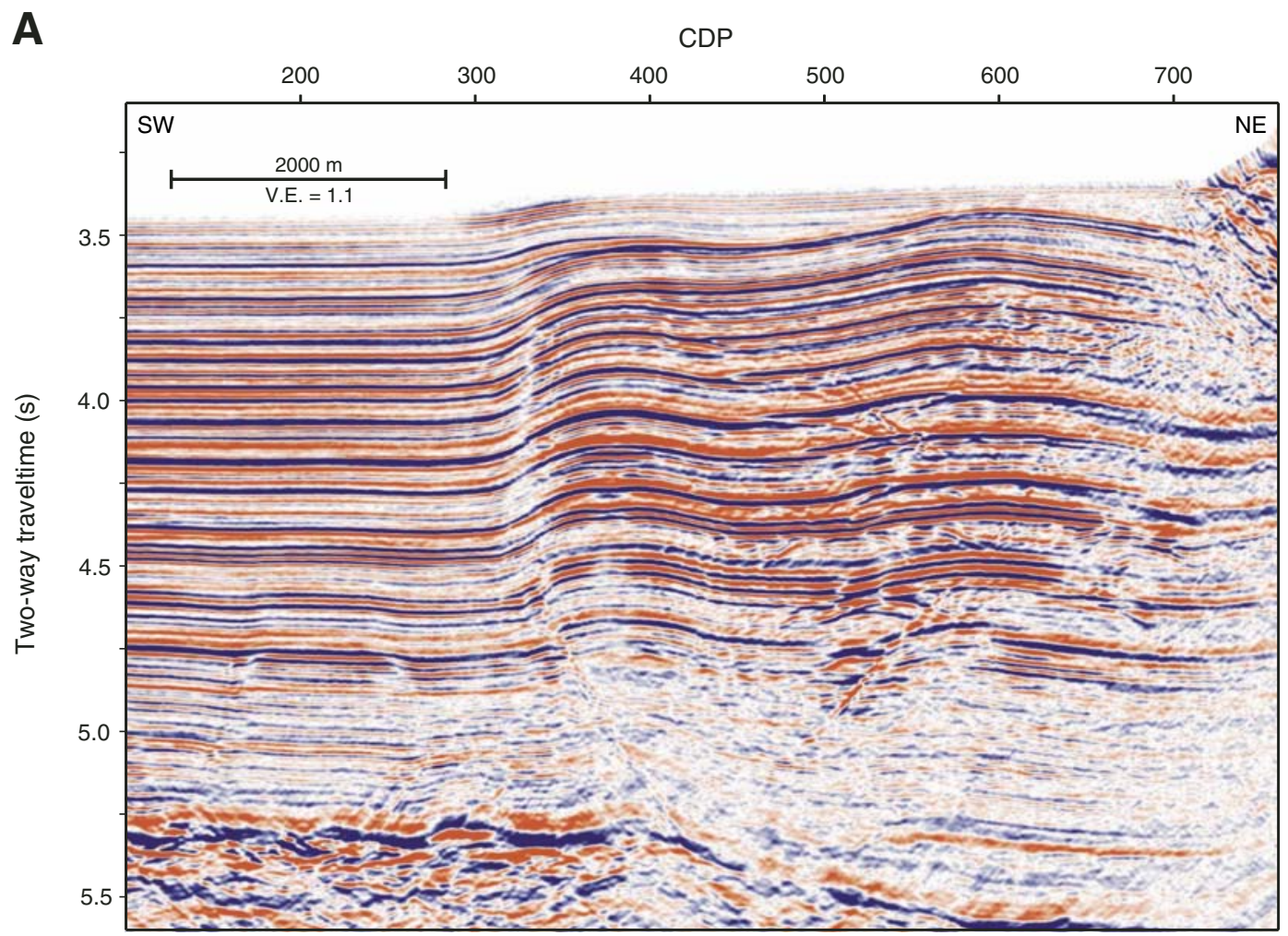

B

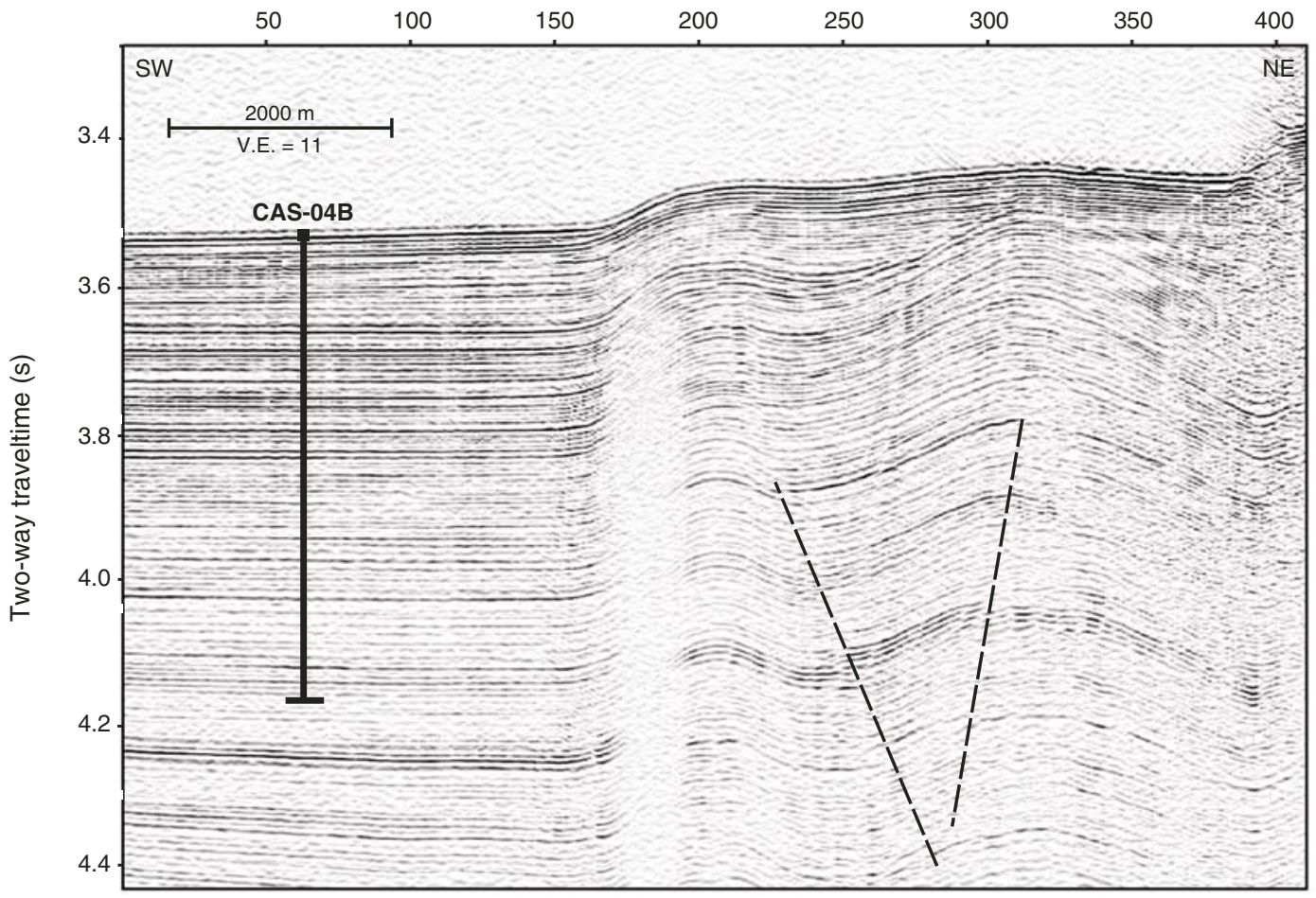


Figure F4. A. Segment of low-frequency MCS Line 89-08 over first frontal ridge at Site U1326, clearly imaging a BSR. Note asymmetric amplitudes across the ridge with the landward side being almost entirely blank. B. Segment of higher-frequency MCS Line ODP-7 over frontal ridge showing no strong BSR. CPD = common depth point, V.E. = vertical exaggeration.
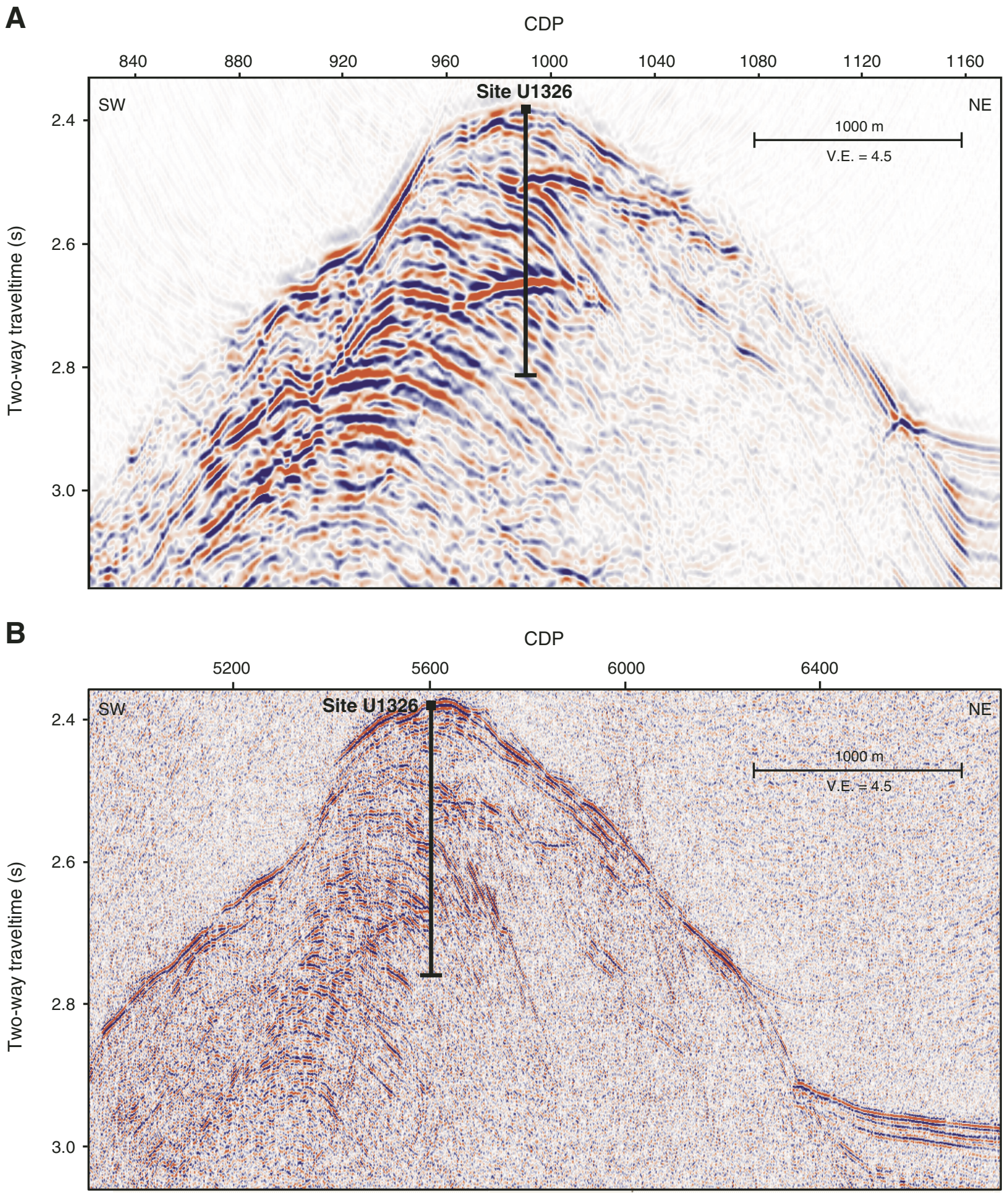
Figure F5. A. Segment of SCS Line PGC0408_CAS03B_X04 crossing Site U1326. Here a clear bottom-simulating reflector (BSR) is seen underneath the summit of the ridge. B. Segment of MCS Line CASO3 imaging the ridge in a northwest-southeast direction. $\mathrm{CPD}=$ common depth point, V.E. $=$ vertical exaggeration .

A

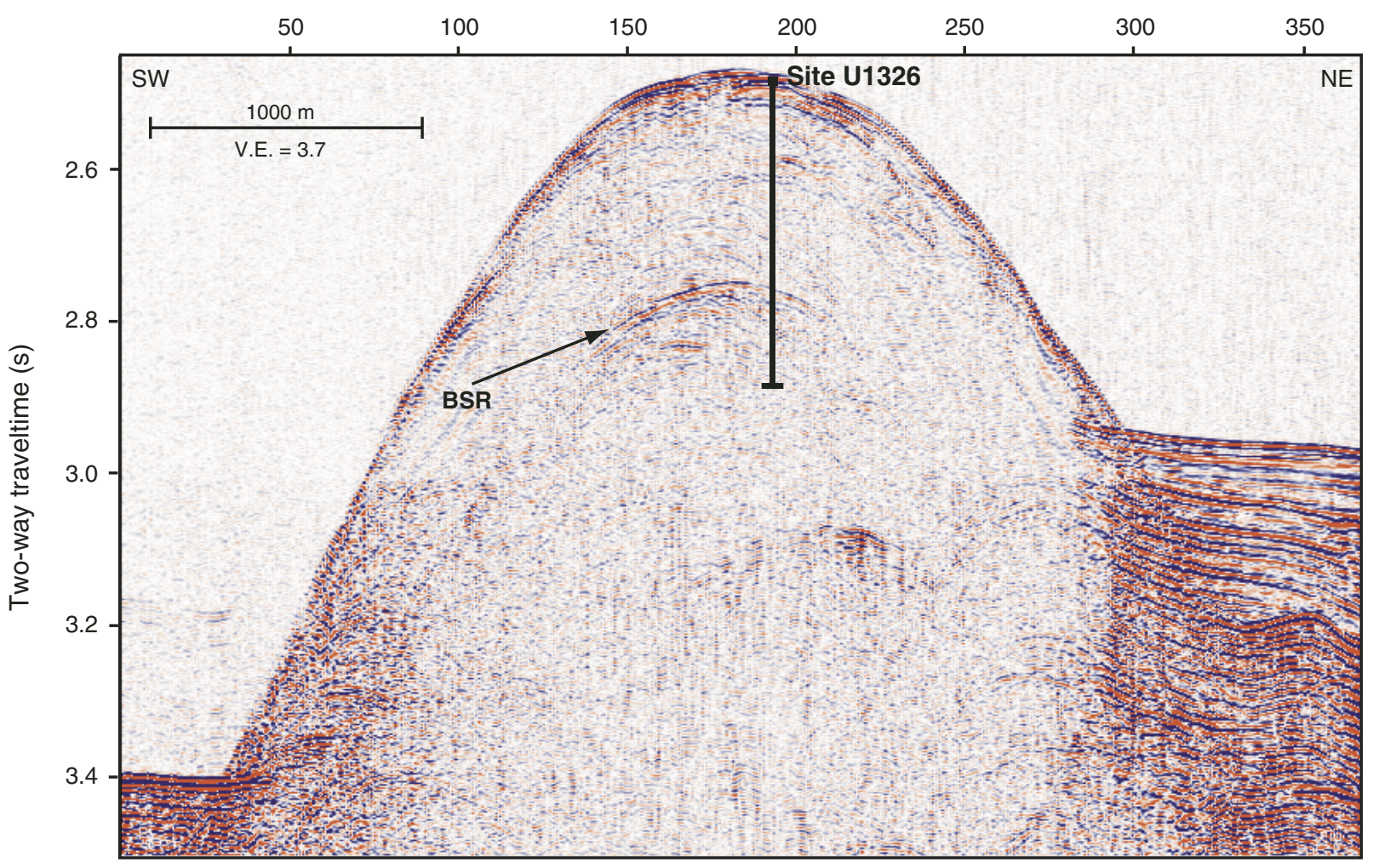

B
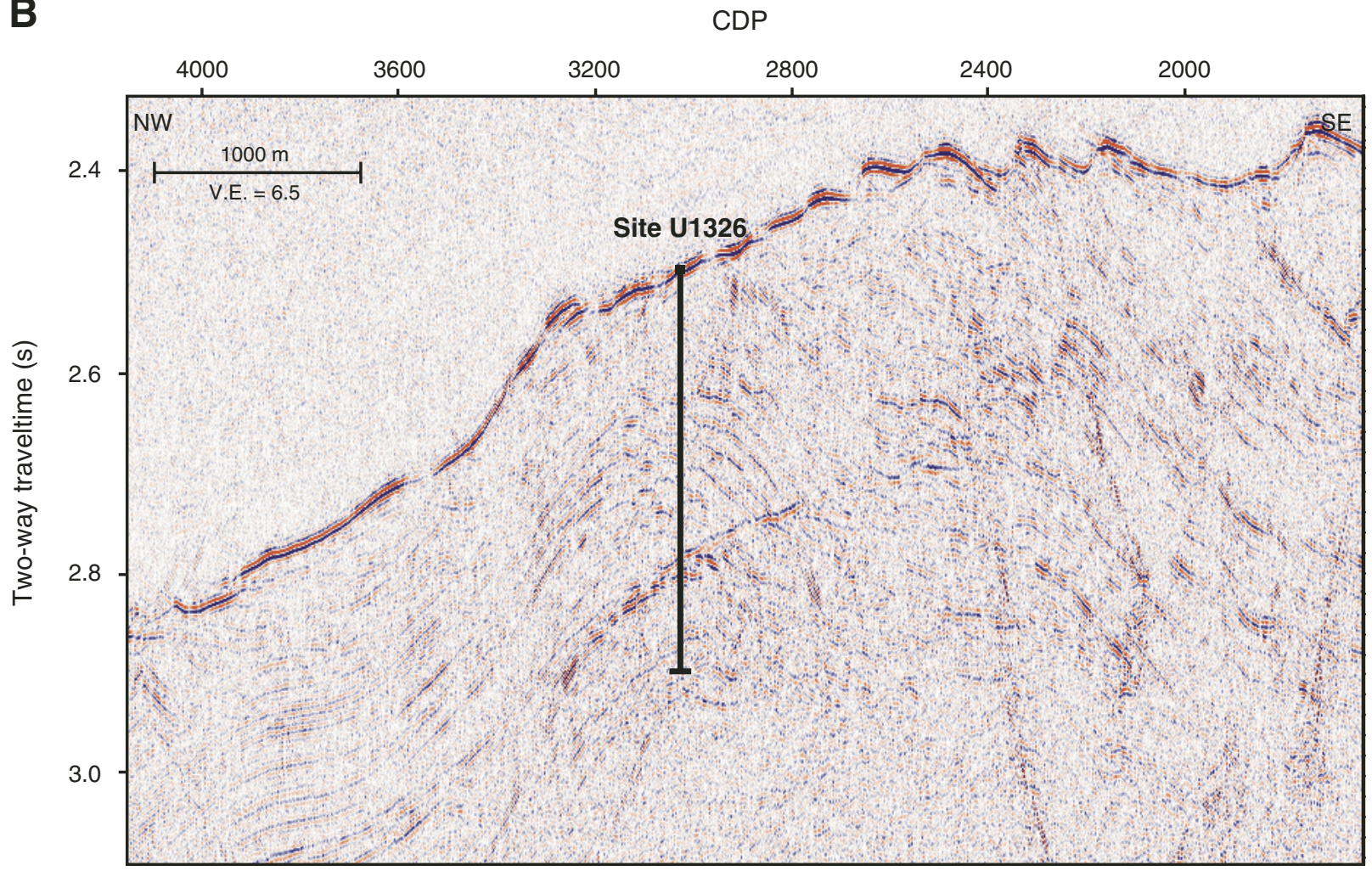
Figure F6. Segment of the $3.5 \mathrm{kHz}$ data acquired in the first slope basin near Site U1325 showing a transparent layer at the seafloor ( 5-7 m thick) representing the most recent Holocene sedimentation. A small blank zone is also identified in the center of the basin on top of a buried ridge of accreted sediments (see Fig. F7A). V.E. = vertical exaggeration.

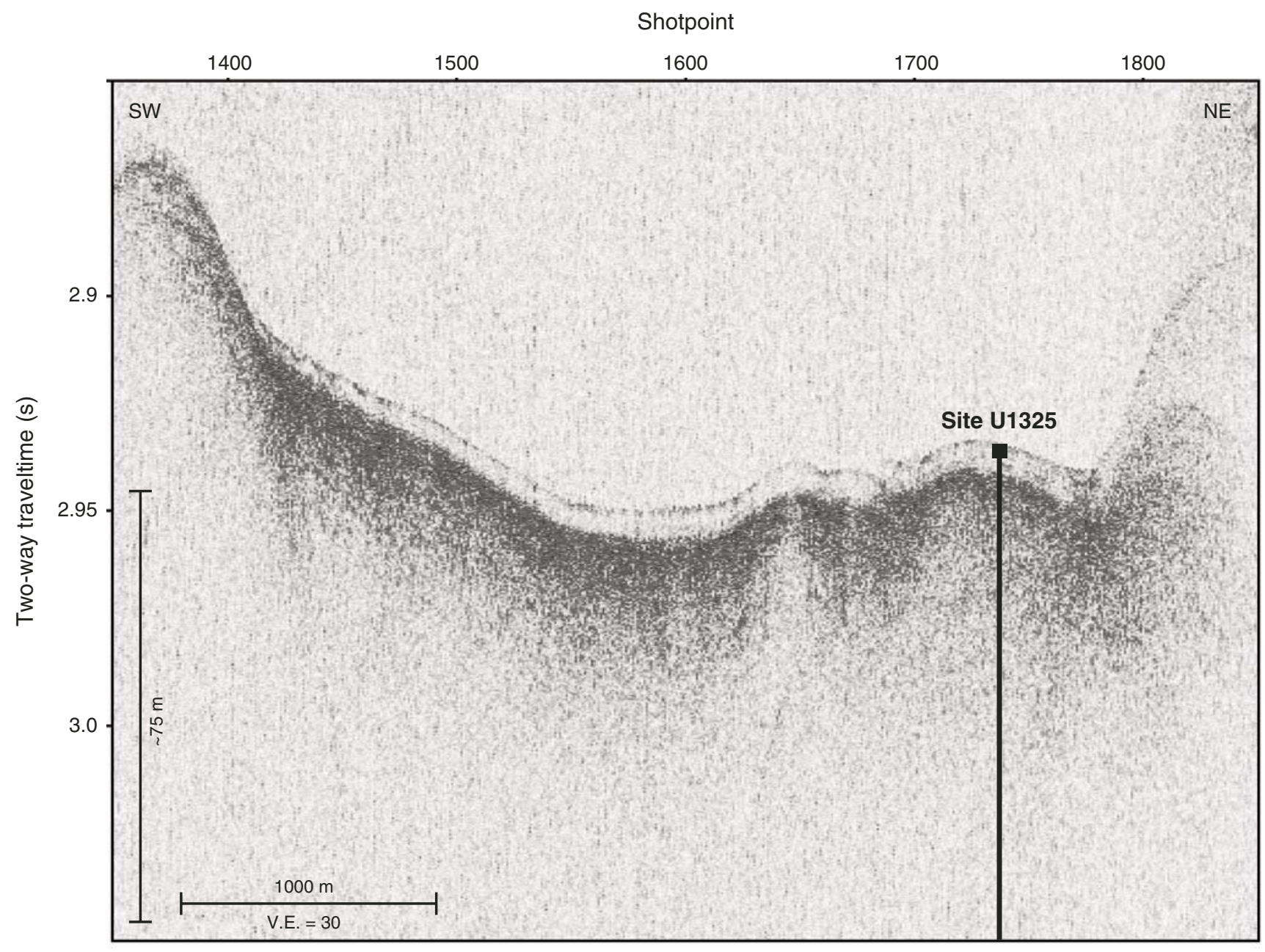


Figure F7. A. Section of low-frequency MCS Line 89-08 over first slope basin near Site U1325. A clear BSR is seen between common depth points (CDPs) 1280 and 1420, around the ridge of accreted sediments. Site U1325 is located away from the core of the ridge, where a bright spot with apparent opposite reflection polarity may indicate the presence of free gas within the gas hydrate stability field. B. Section of the coincident higher frequency MCS Line ODP-7 showing a much reduced BSR reflection. V.E. = vertical exaggeration.
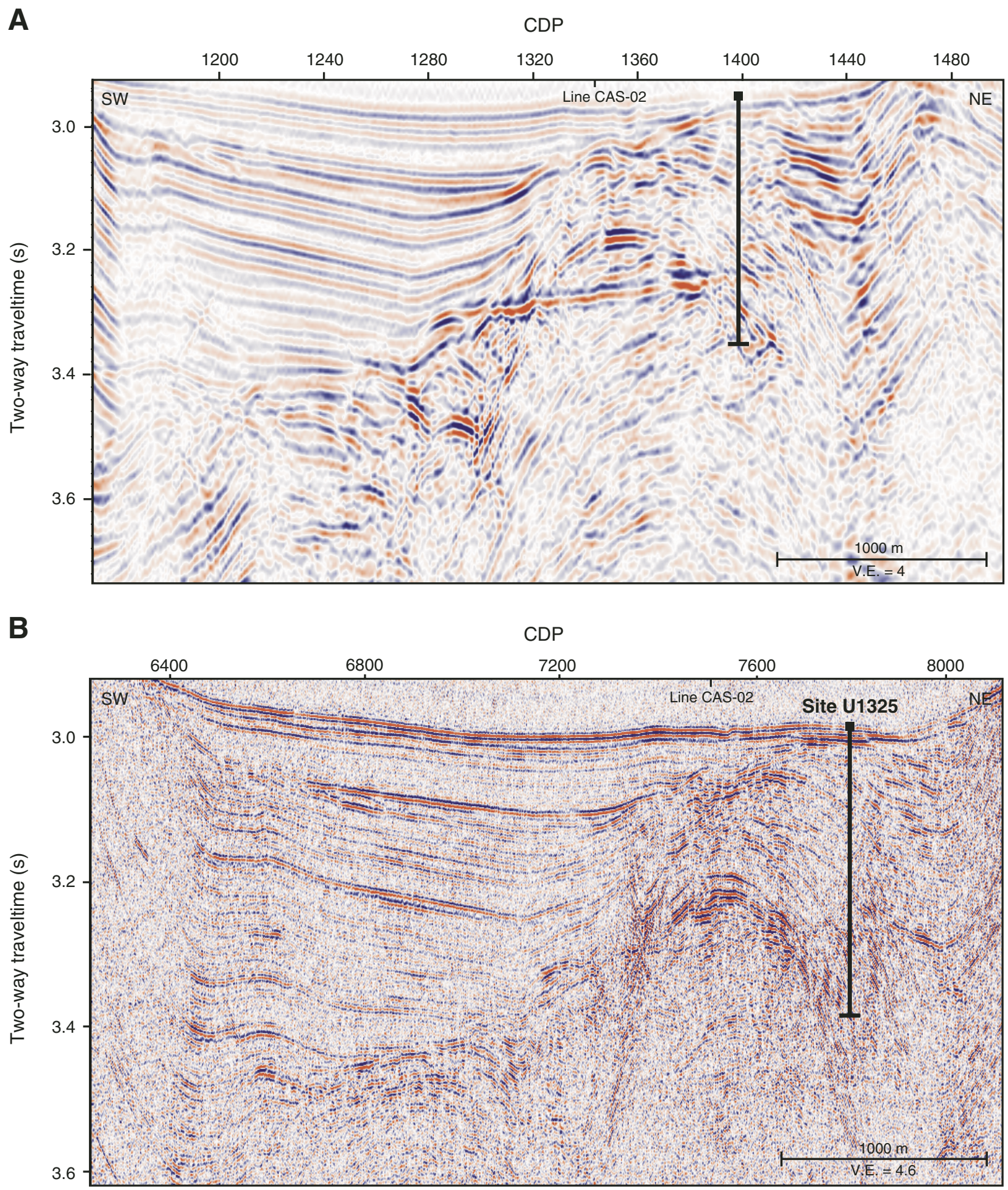
Figure F8. A. Section of higher frequency Line CAS-02 (COAMS data) acquired perpendicular to the main transect through the originally proposed site location (see Fig. F7). B. SCS Line PGC0408_CAS02B_05 crossing perpendicular to Lines 89-08 and ODP-7 at Site U1325. No clear BSR can be identified on this line, which is $650 \mathrm{~m}$ northeast of Line CAS-02. CPD = common depth point, V.E. = vertical exaggeration.

A

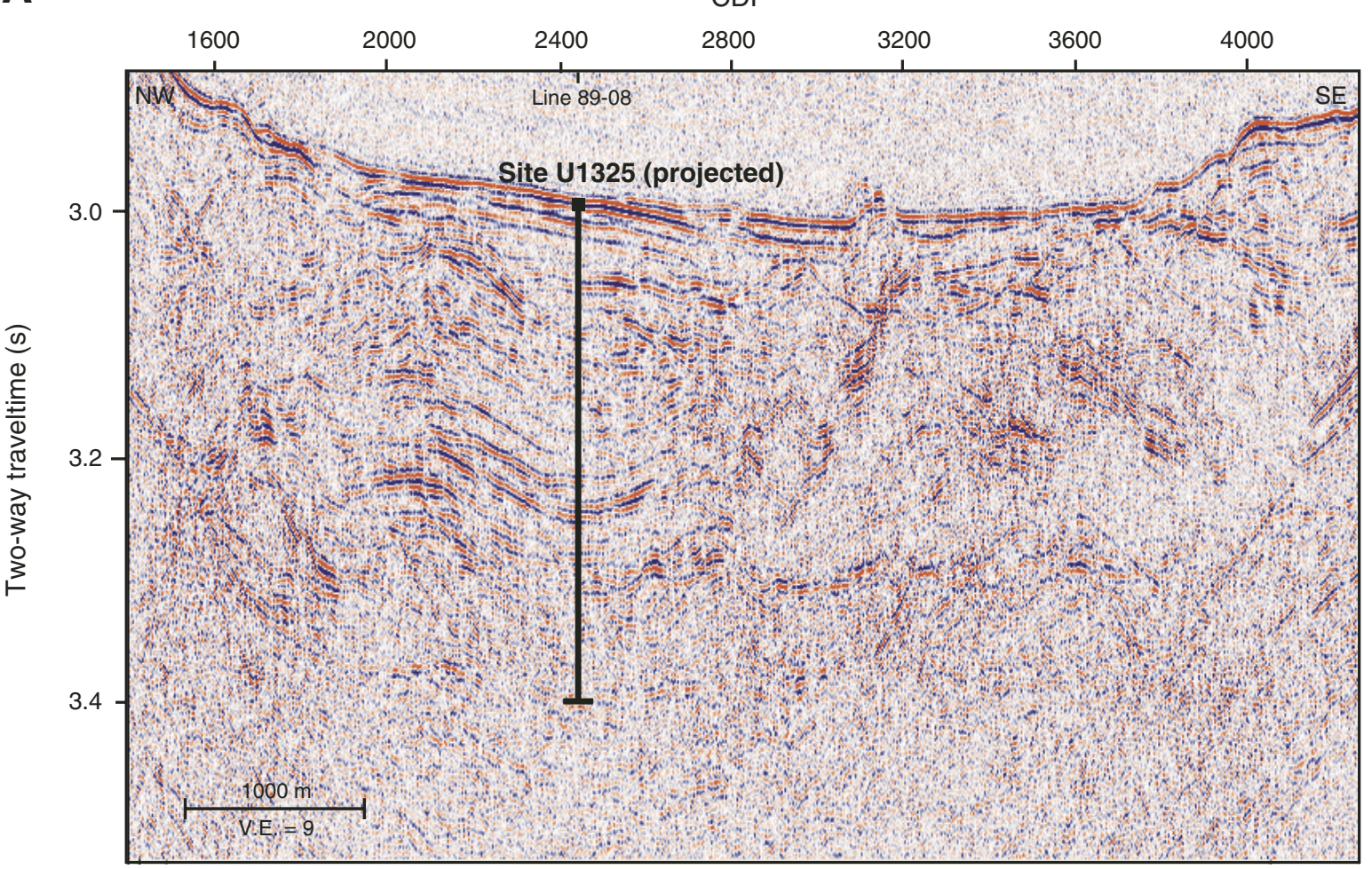

B

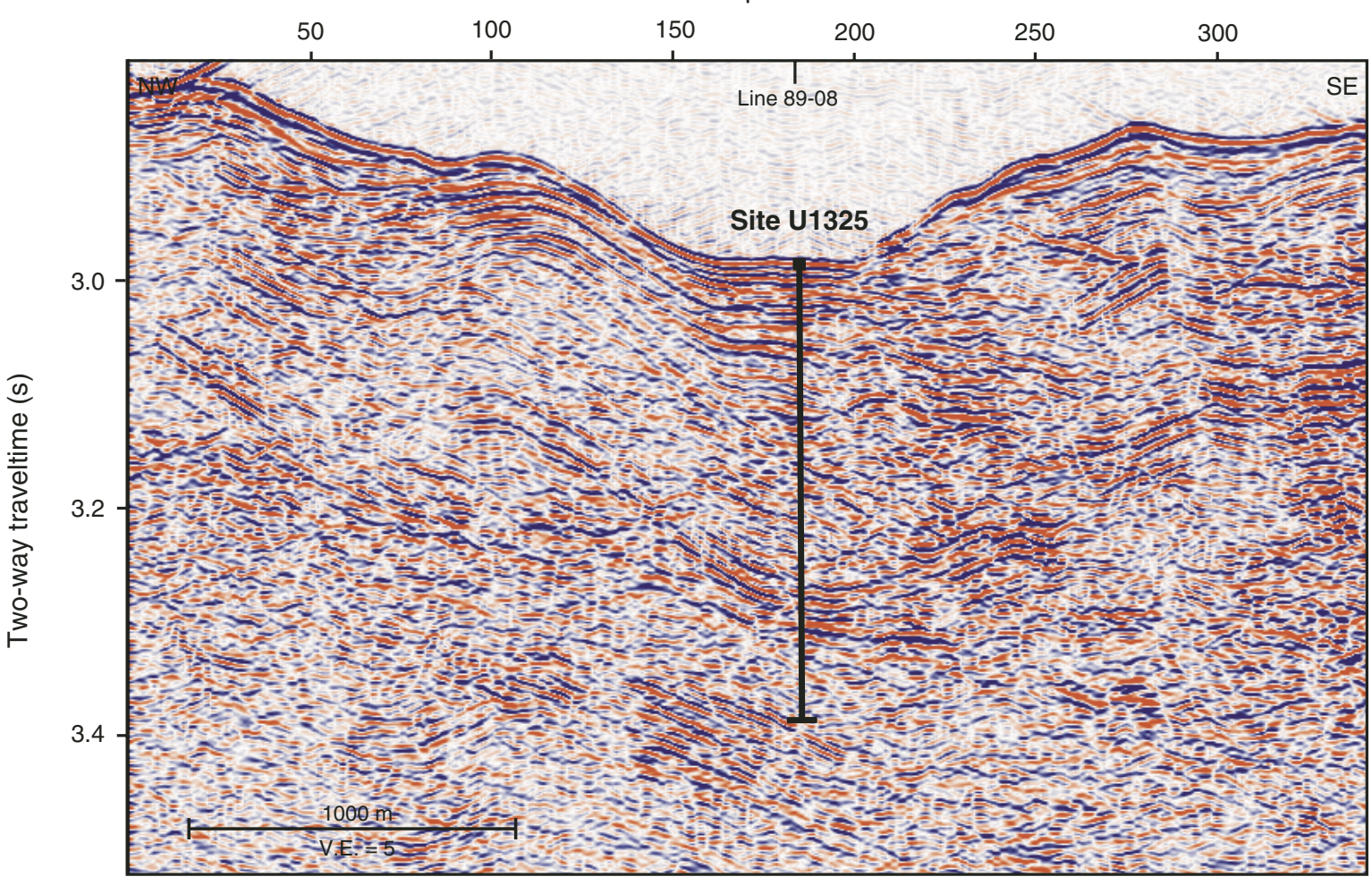


Figure F9. $3.5 \mathrm{kHz}$ data acquired along multichannel seismic (MCS) Inline 38 of the pseudo 3-D grid of Cruise PGC9902. In the northwest portion of the section (up to Shotpoint 300), a transparent layer of Holocene sediments is visible; however, it is absent over Site U1327 and the entire remaining portion of the line. V.E. = vertical exaggeration.

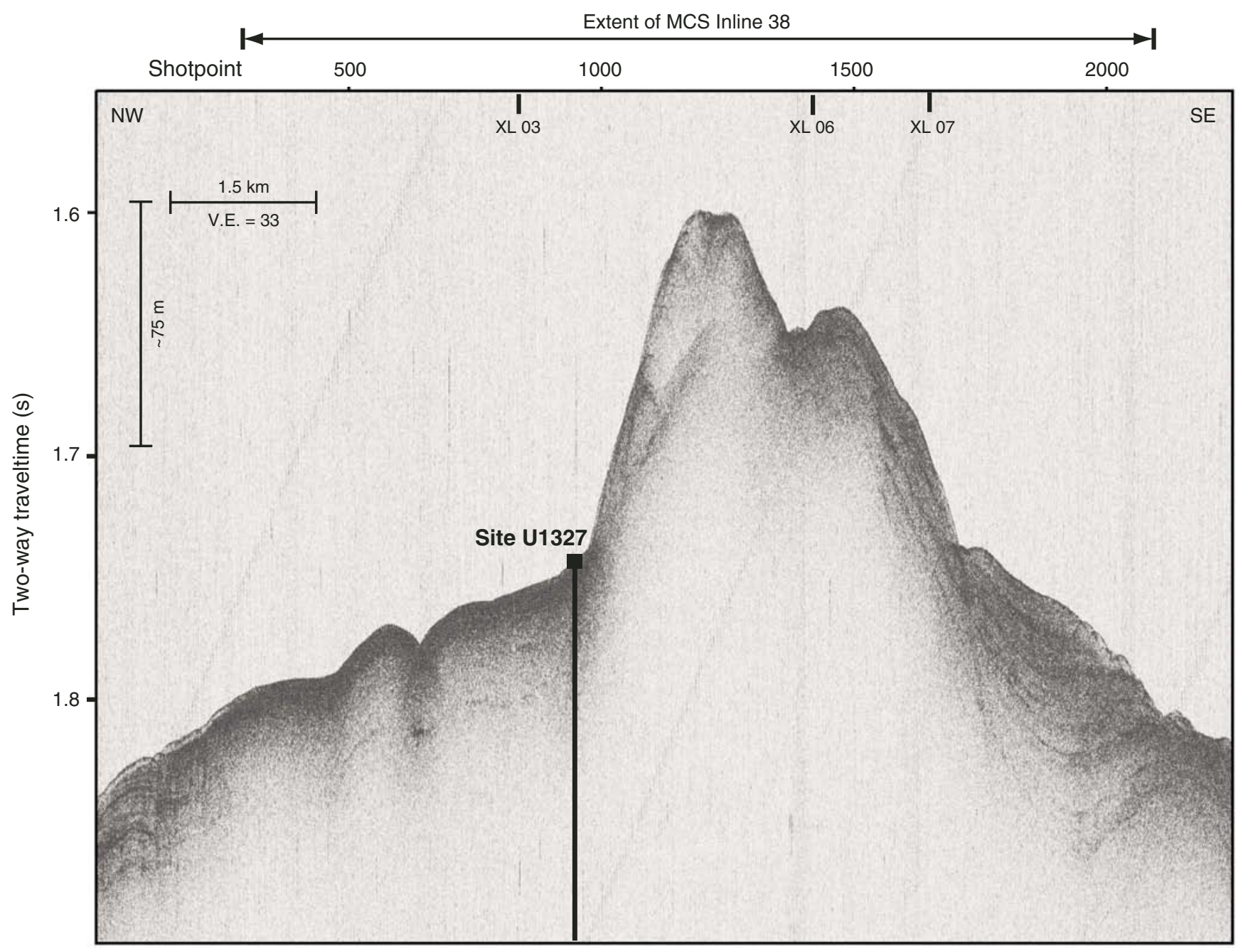


Figure F10. A. Time-migrated section of Inline 38 (COAMS data) of the pseudo 3-D grid. A clear BSR is present below the topographic high, formed of accreted sediments. A clear boundary between the reflective slope basin sediments and the seismically incoherent accreted sediments is imaged. The boundary between these two types was mapped over the 3-D grid and is shown in Figure F11B. CPD = common depth point. B. SCS Line PGC0503_CAS01B_02, parallel to and $500 \mathrm{~m}$ south of MCS Line 89-08. V.E. = vertical exaggeration.

A

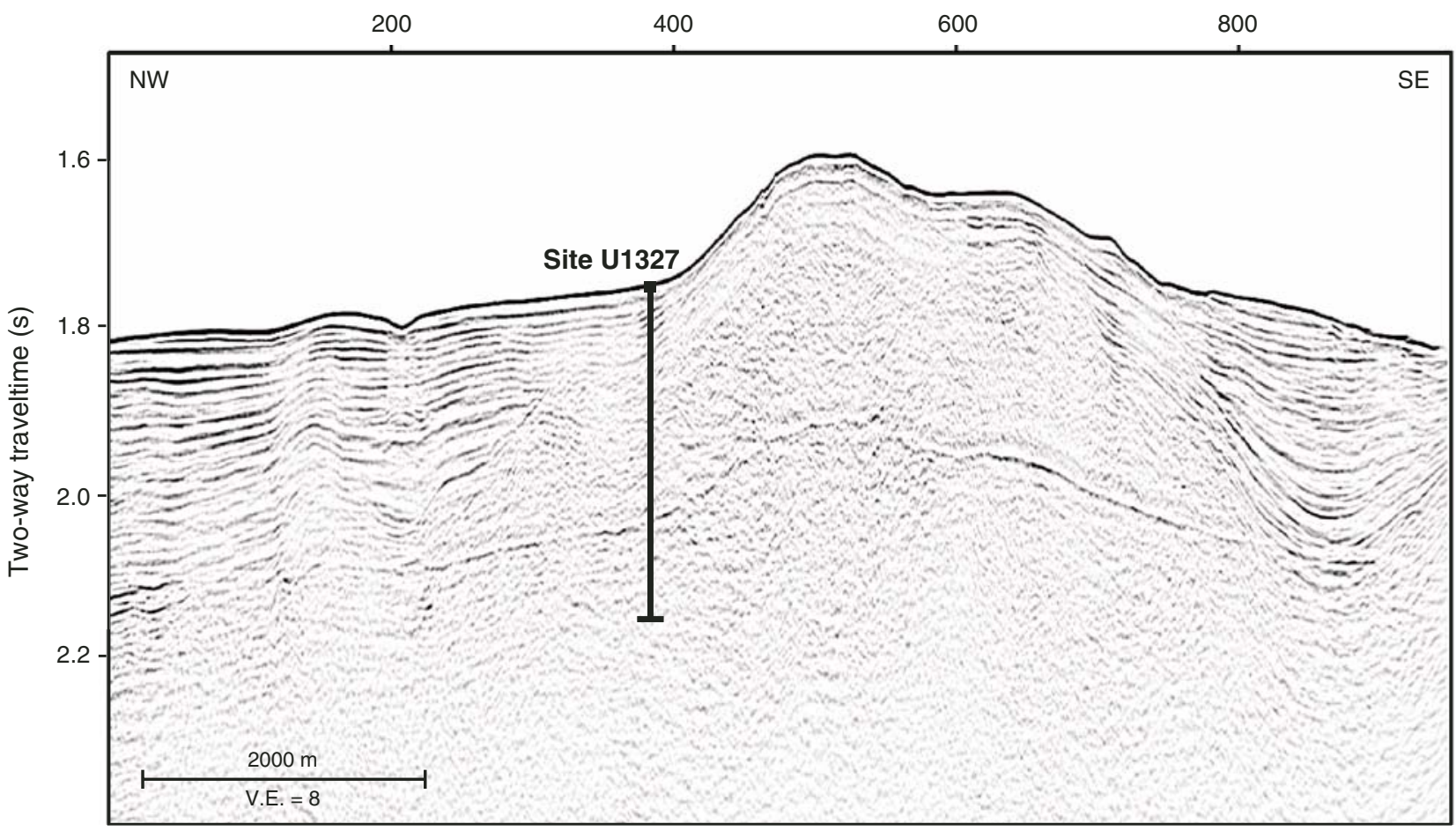

B

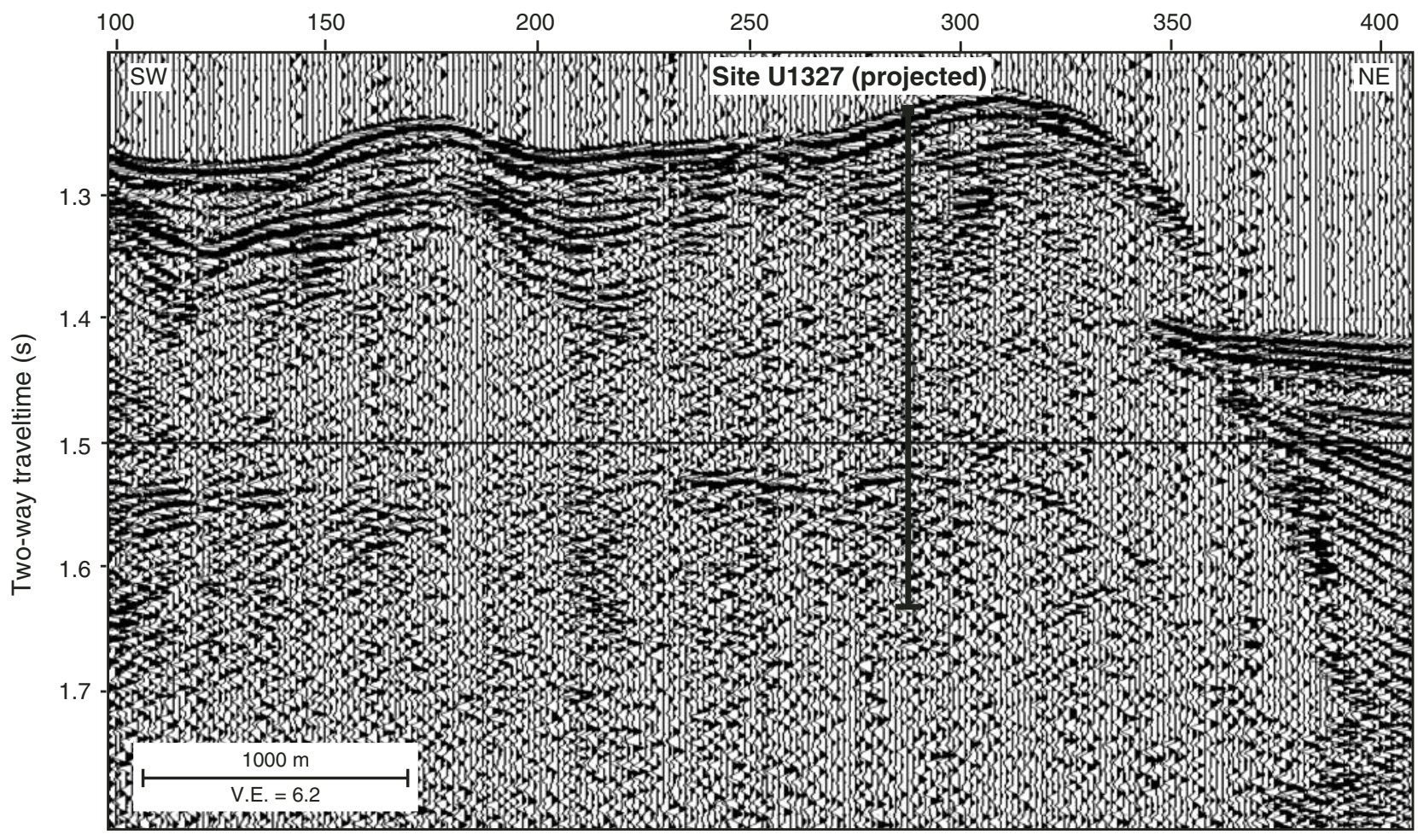


Figure F11. (A) Bottom-simulating reflection (BSR) coefficients derived from the pseudo 3-D grid and (B) the extent of the boundary between accreted and slope-basin sediments. A clear BSR bright spot is seen within a trough of the boundary between the two main types of sediment.

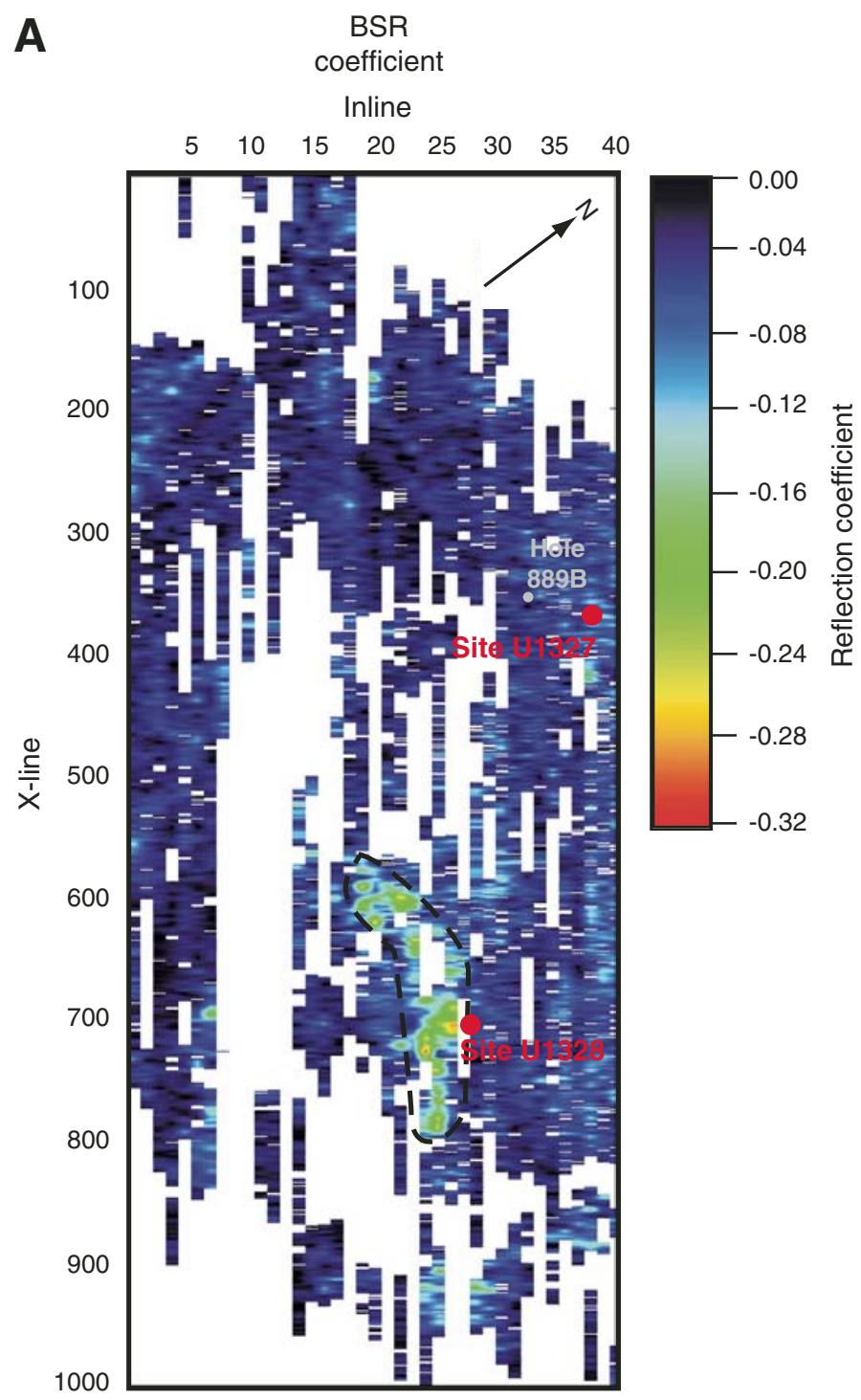

B Boundary between accreted
and slope sediments

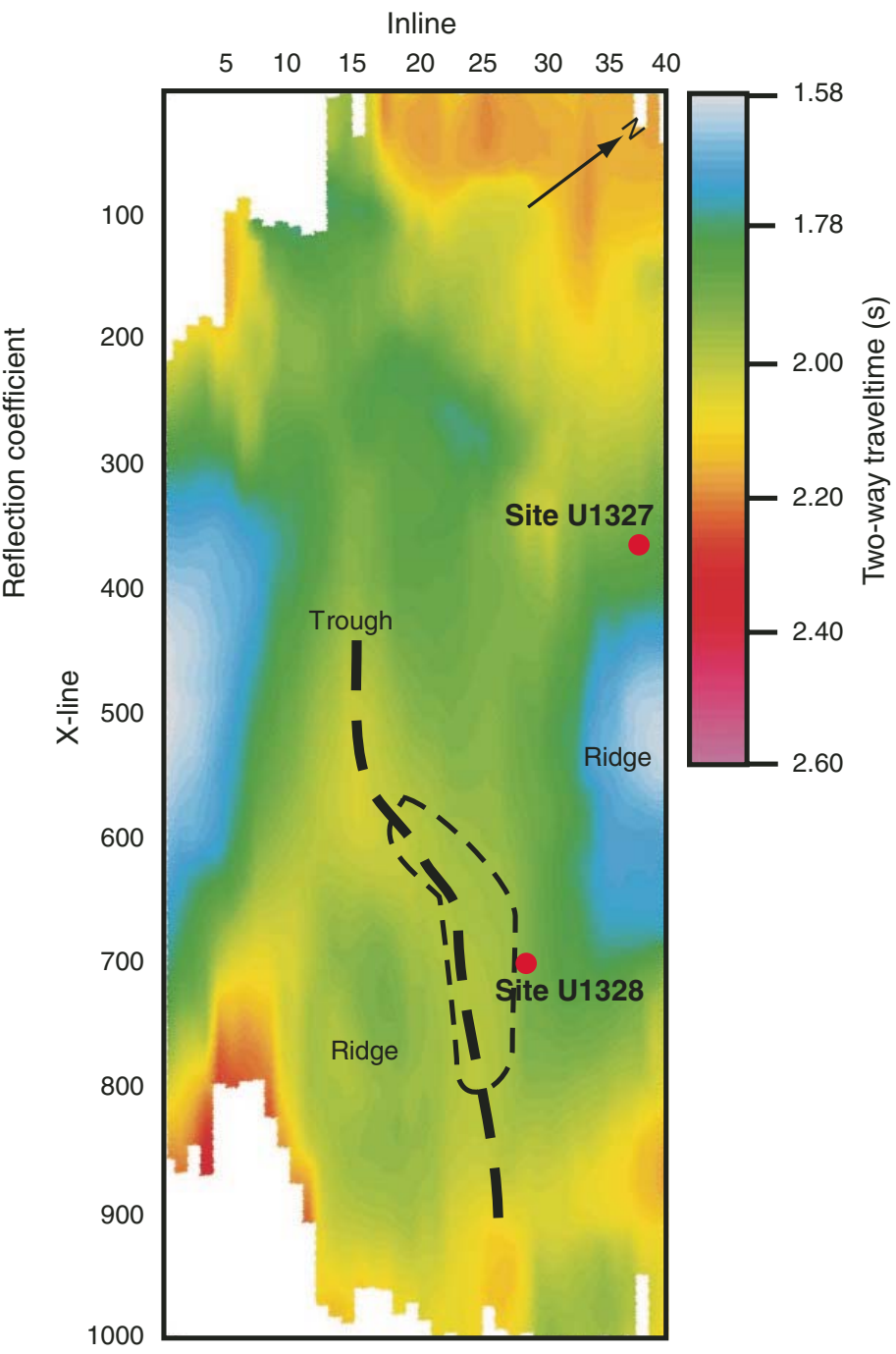


Figure F12. A. Section of low-frequency MCS Line 89-08 over Site U1329. A BSR is evident up to common depth point (CDP) 3300. No clear BSR is identifiable for the remaining profile. B. Section of higher frequency MCS Line ODP-01 over Site U1329 showing a faint reflection in the upper slope section interpreted as a BSR. V.E. = vertical exaggeration.

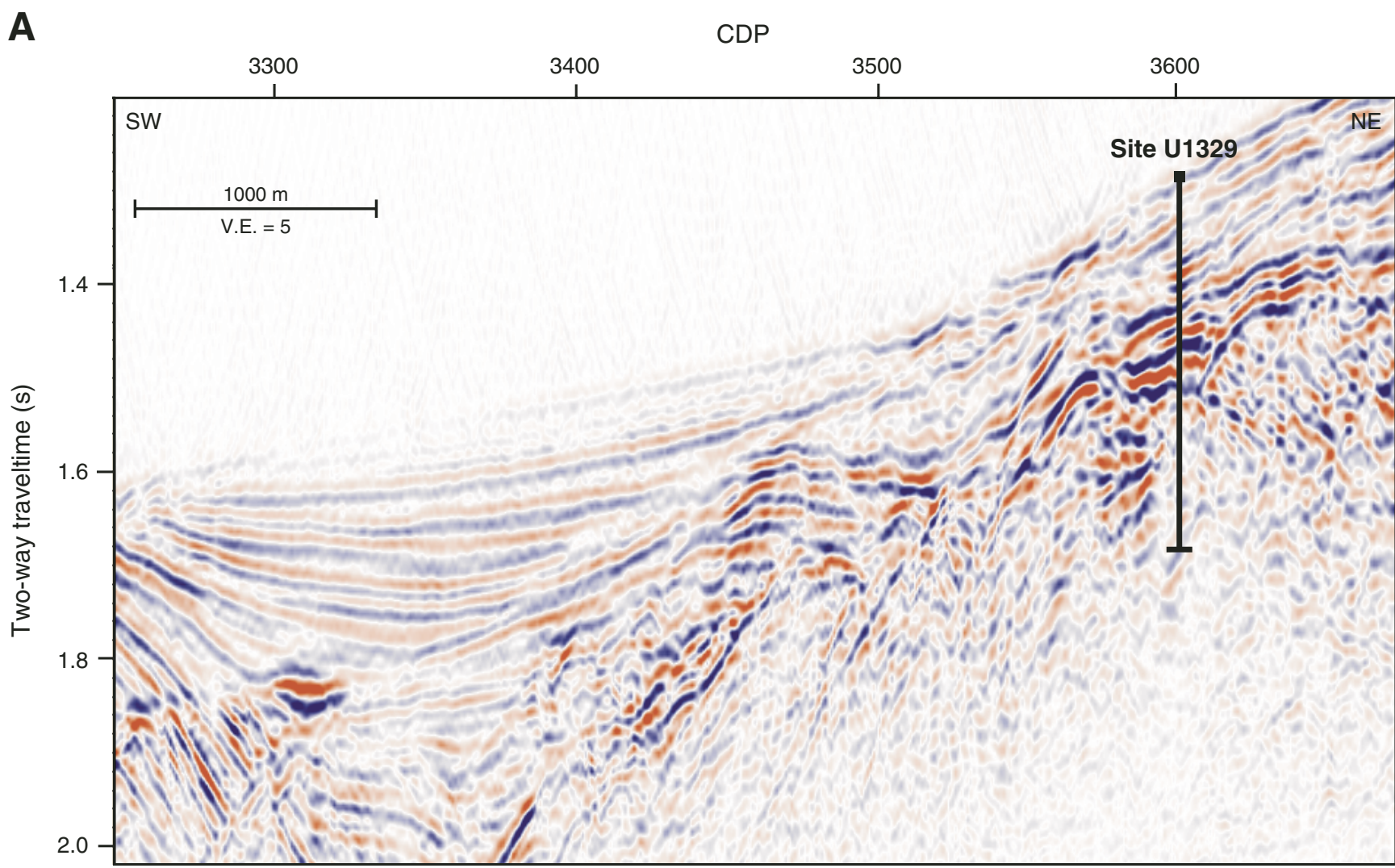

B

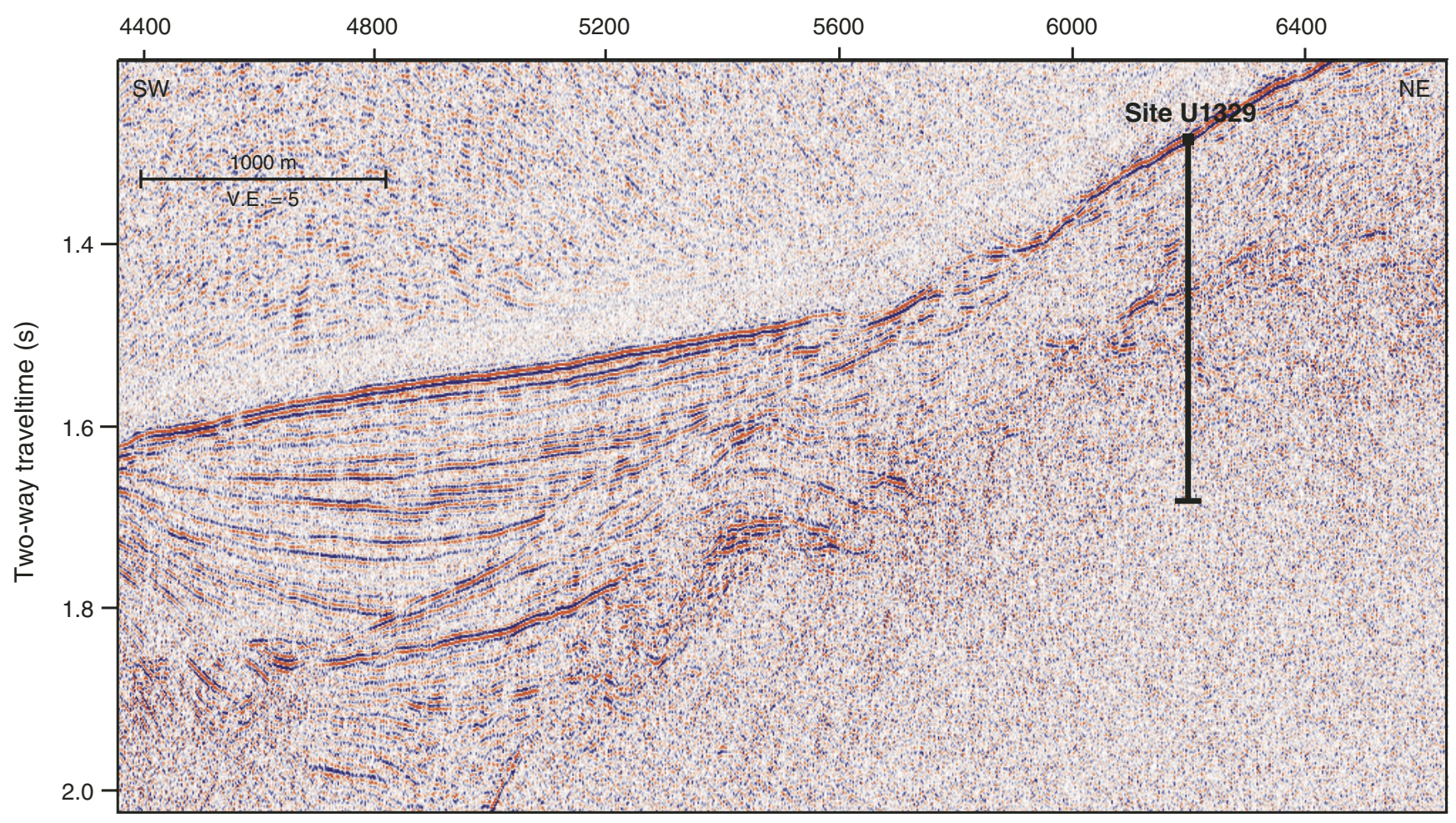




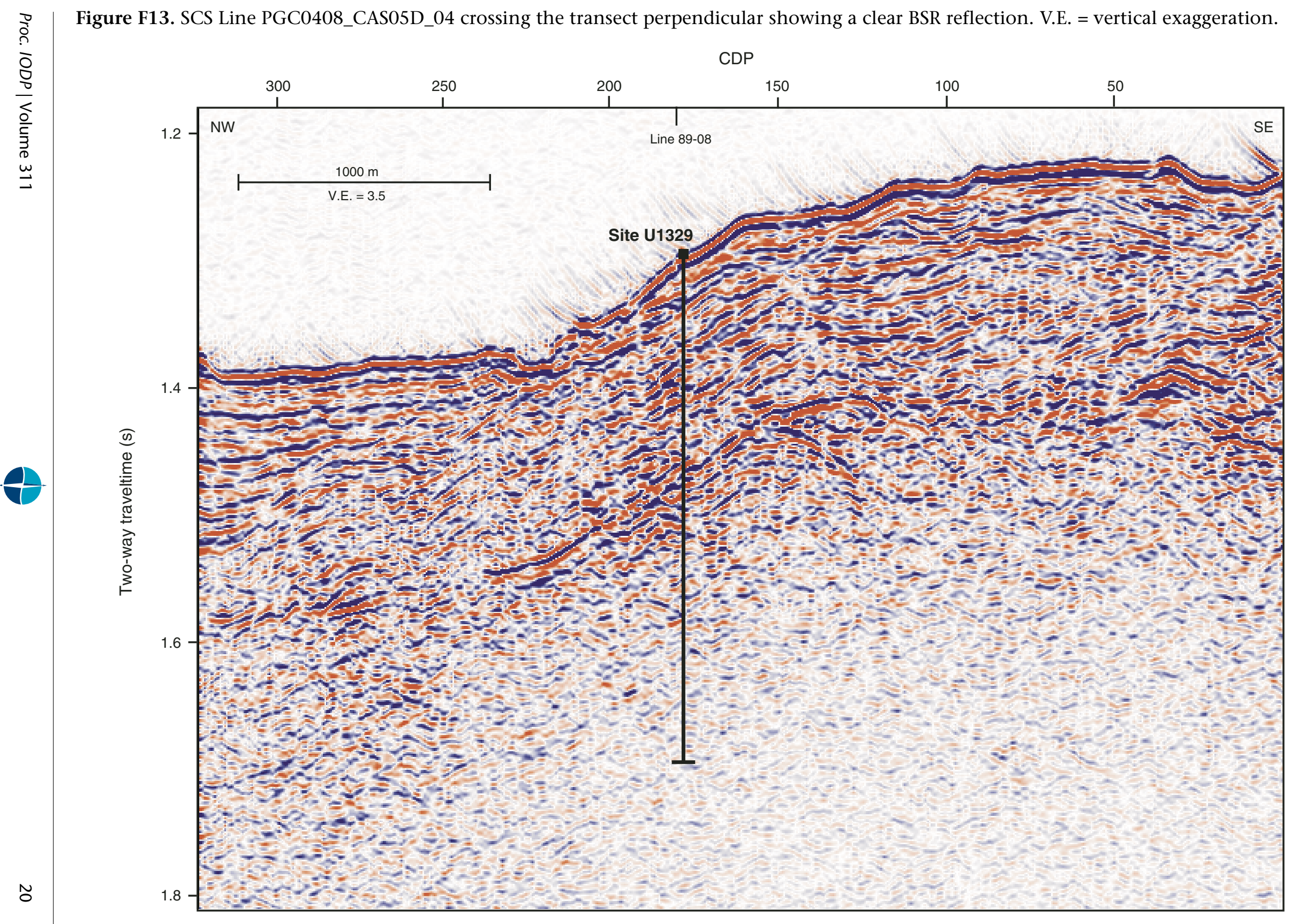



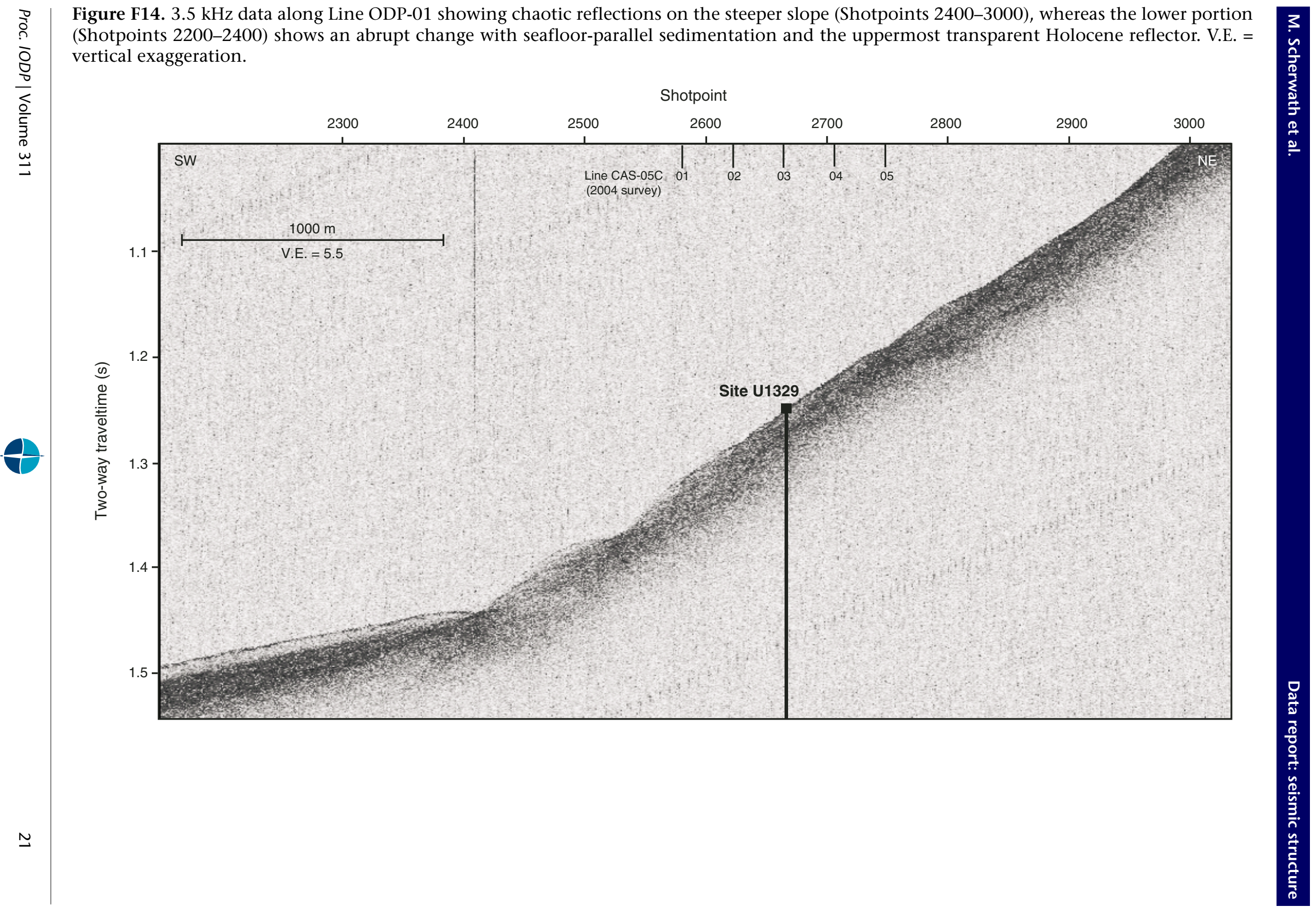
Figure F15. $3.5 \mathrm{kHz}$ data over cold vent field clearly showing four seismic blank zones. Over blank Zone 1 (also referred to as Bullseye vent) at Site U1328, a seafloor expression of a mud/carbonate mound is seen, with an elevation of $\sim 6$ m. V.E. = vertical exaggeration.

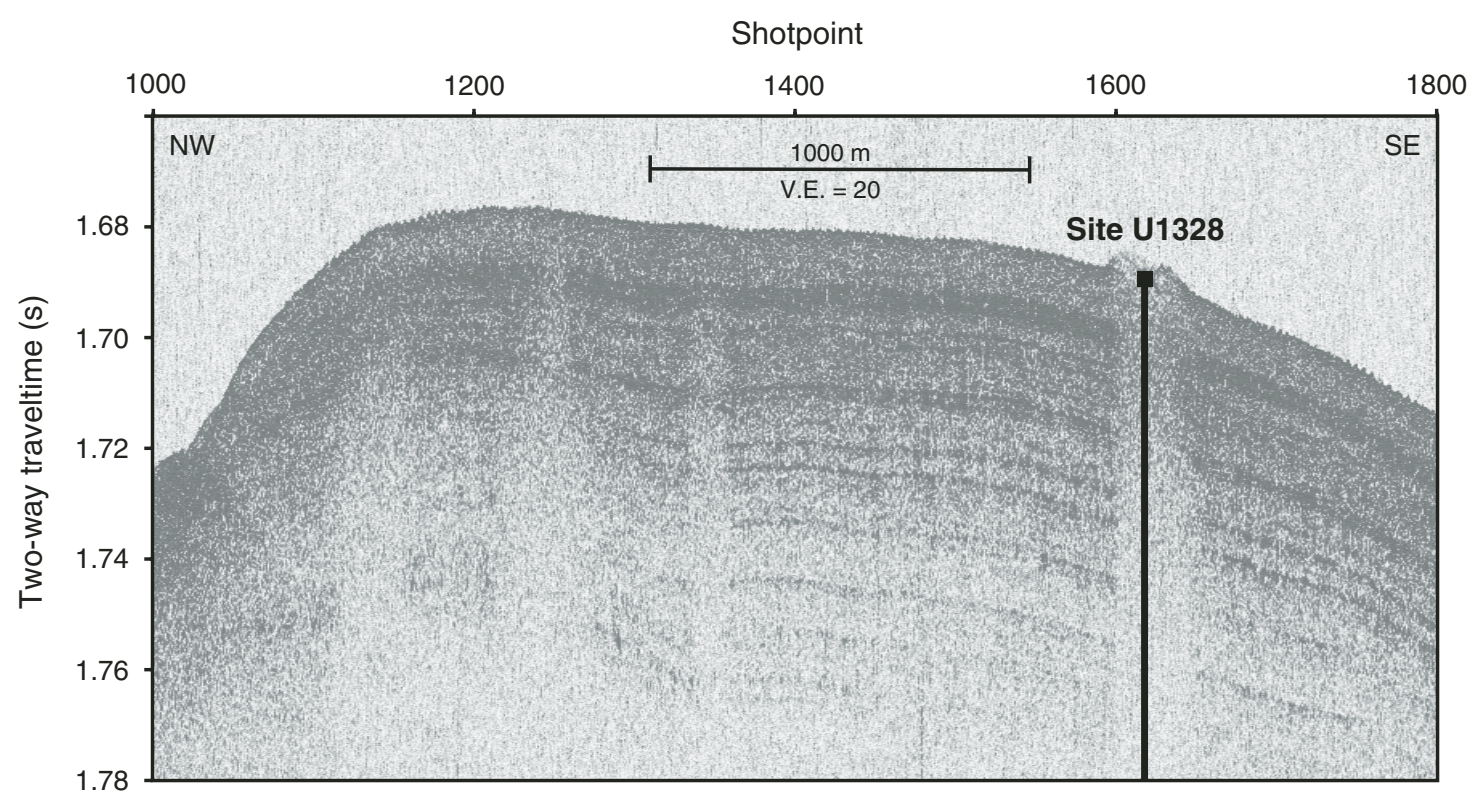


Figure F16. A. Section of COAMS Inline 27 (time-migrated) over vent field and Site U1328. Four blank zones are visible; however, the amount of blanking is reduced relative to the $3.5 \mathrm{kHz}$ data. $\mathbf{B}$. Section of MCS Line XL-07 (COAMS data) crossing Site U1328 in an east-west direction perpendicular to Inline 27. CPD = common depth point, V.E. = vertical exaggeration, BSR = bottom-simulating reflector.

A

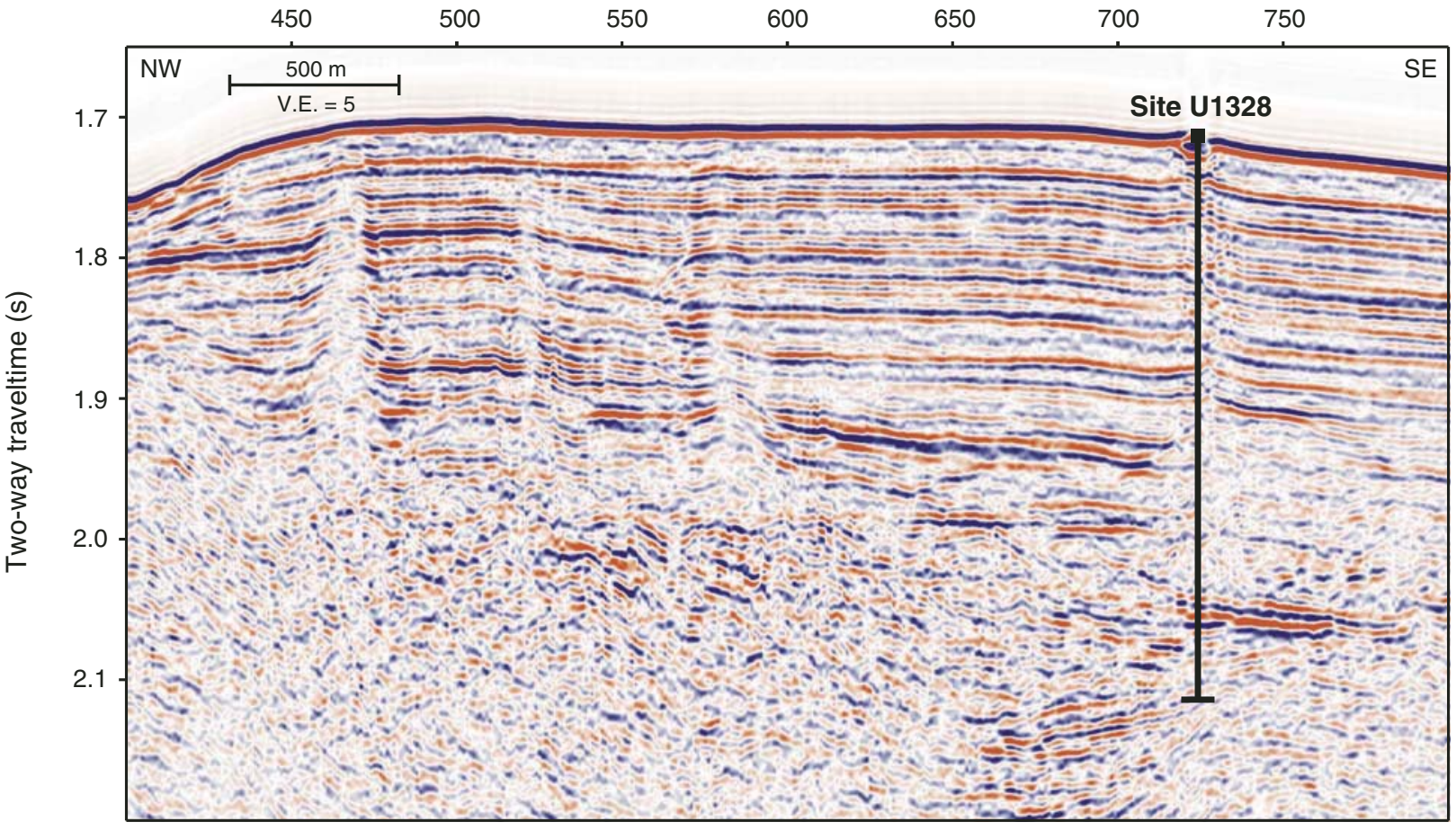

B

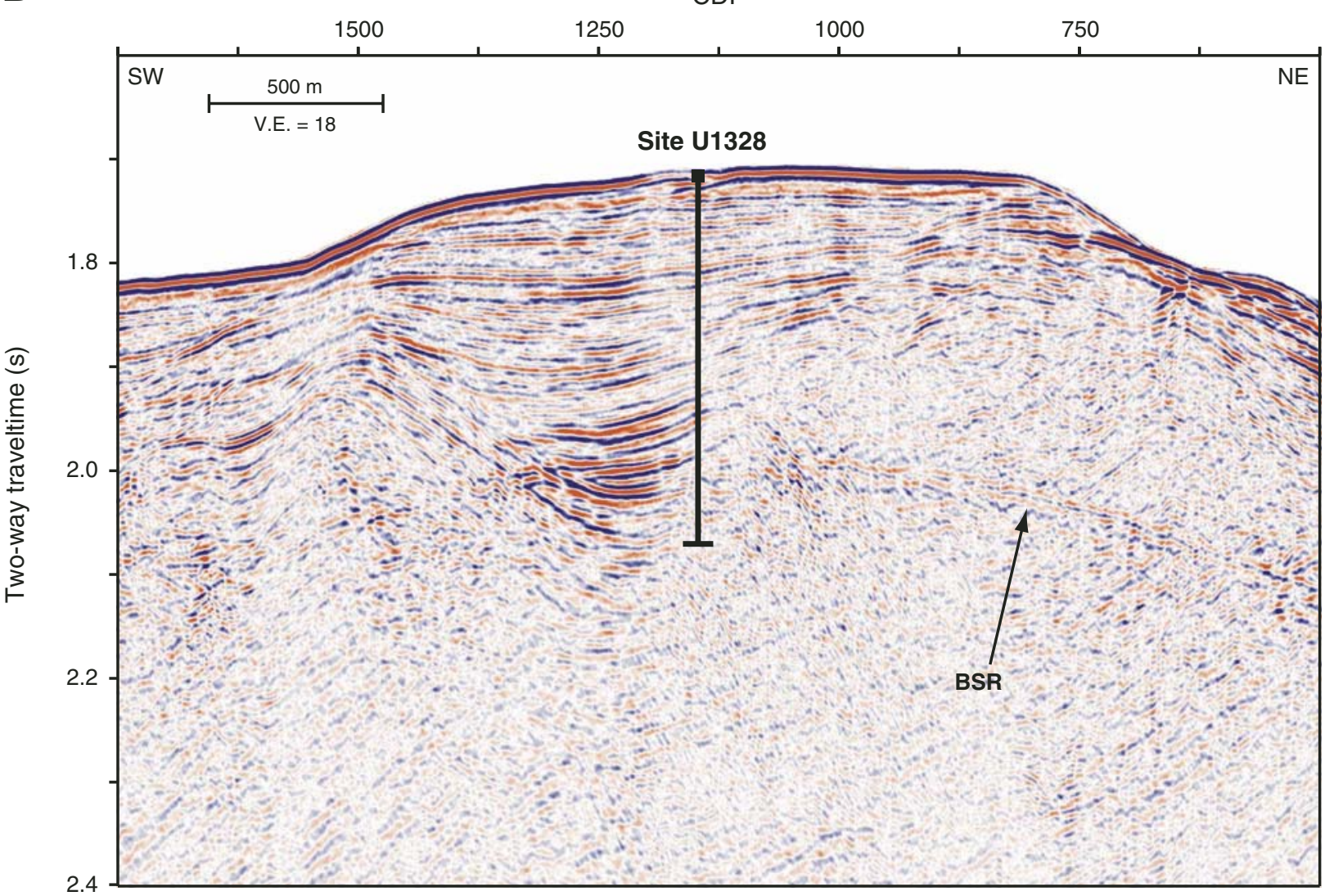


Figure F17. A. Seismically derived reflection coefficients (RC; from 2000 SCS grid) showing reduced reflectivity in the center of Bullseye vent. Locations of piston cores, live chemosynthetic communities, and conductivity-temperature-depth (CTD) casts are shown. B. Time slice at $1.75 \mathrm{~s}$ two-way traveltime through the $2000 \mathrm{SCS}$ grid using the instantaneous amplitude attribute. A ring of high-reflection amplitude surrounds the center of the blank zone (hence the name Bullseye vent). The seismically imaged top of the massive gas hydrate layer is shown on the map as depth contour lines. C. Cross-section of top of massive gas hydrate layer at Bullseye vent. Axes are universal transverse Mercator (UTM) projection easting and northing coordinates using the WGS-84 reference. $\mathrm{MCS}=$ multichannel seismic, $\mathrm{XL}=$ cross line.

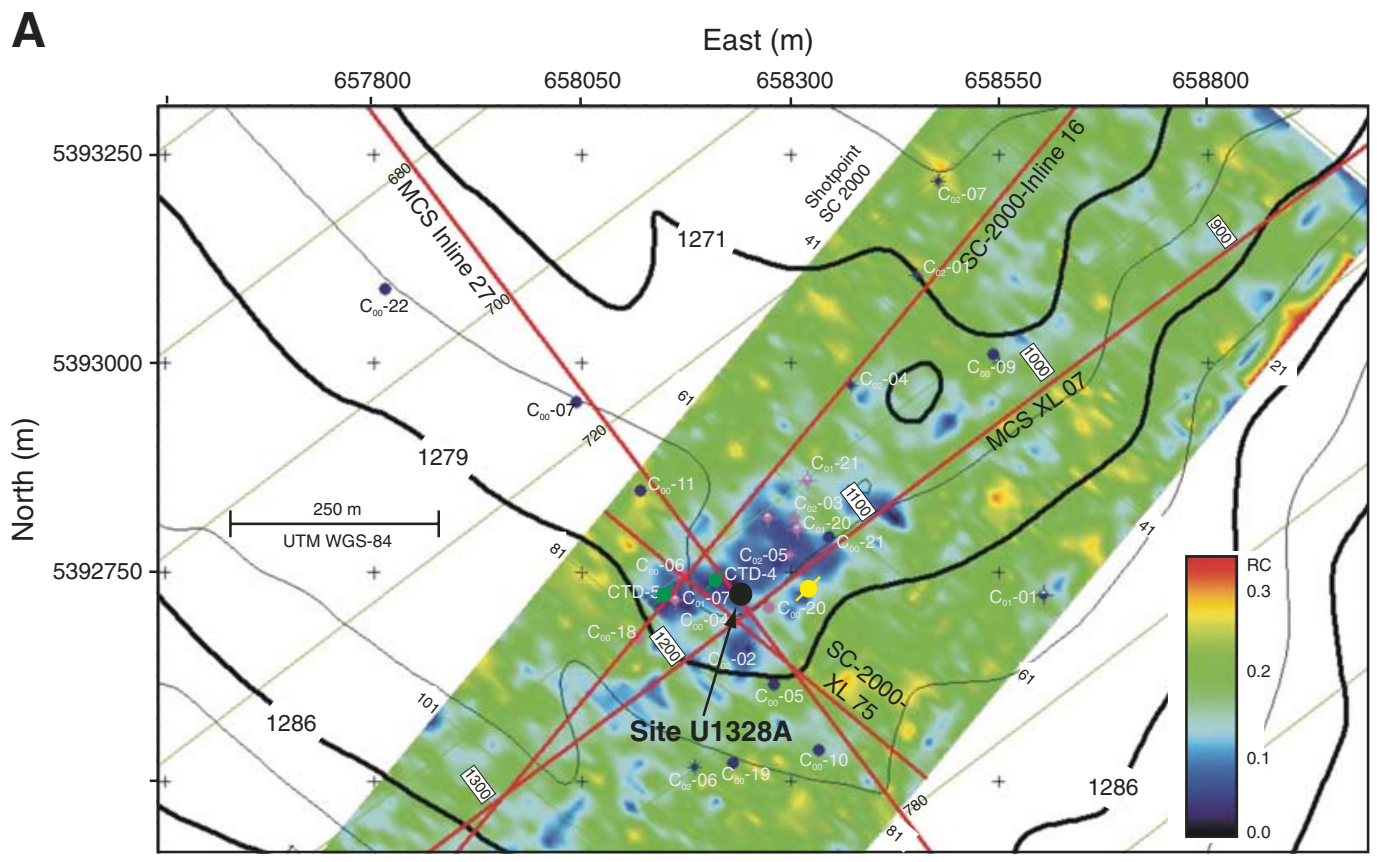

B

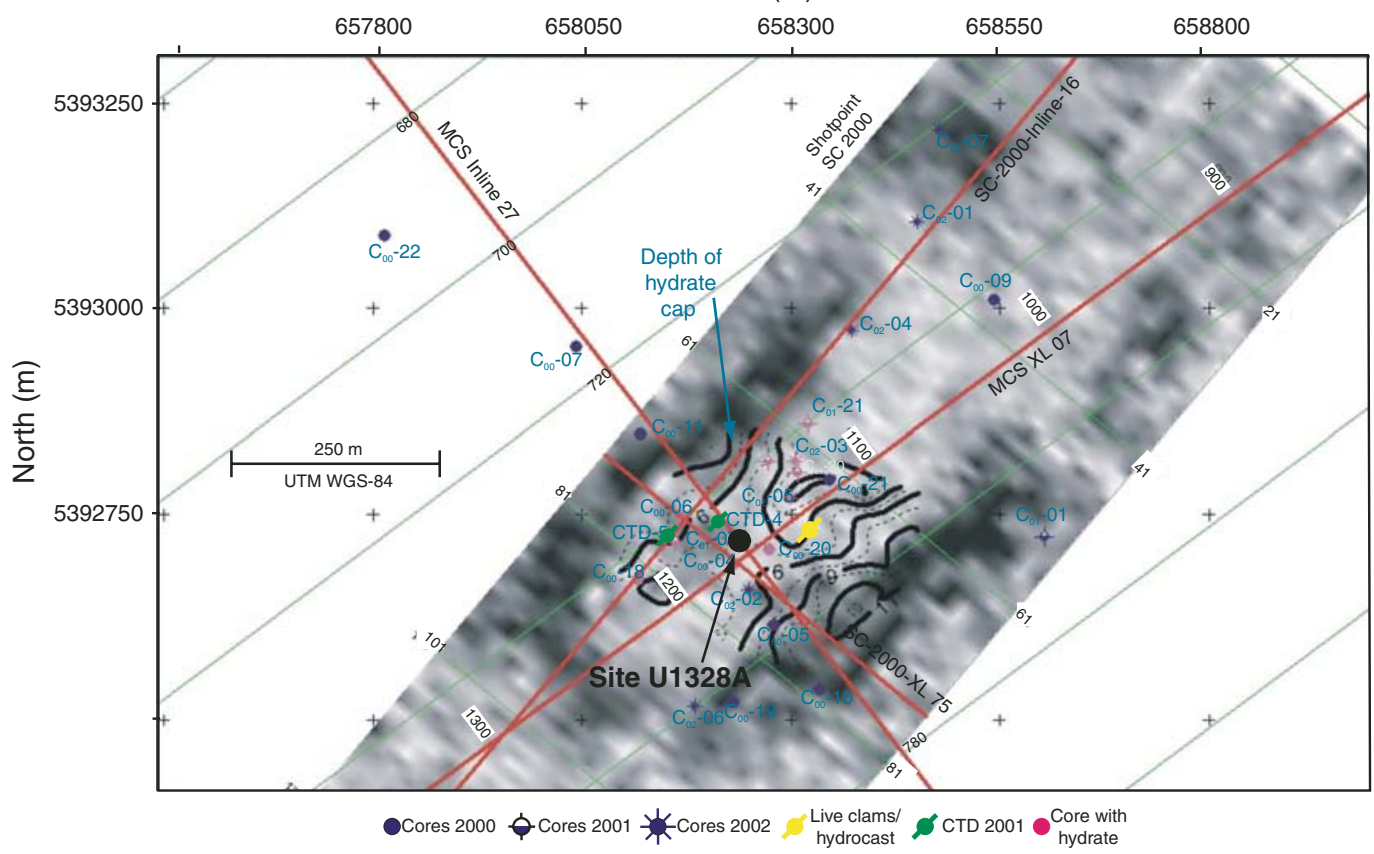

C

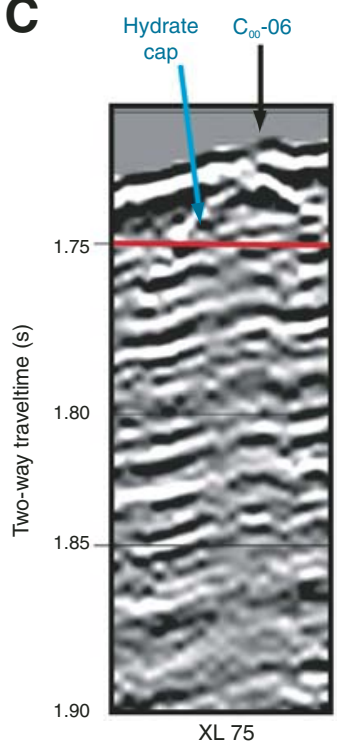


Table T1. Data processing sequence.

\begin{tabular}{ll}
\hline \multicolumn{1}{c}{ Stage } & \multicolumn{1}{c}{ Details } \\
\hline Preprocessing & Localizing hydrophone streamer with AEL; assigning geometry to traces \\
Bandpass filter & Frequency range of $80-250 \mathrm{~Hz}$ for fine structure or 30-140 Hz mainly for BSR \\
Deconvolution & 200 ms filter length \\
& 10 ms gap length \\
& $10 \%$ white noise \\
Bandpass filter & As above \\
Spatial linear signal detector & Velocity filtering in Tau-p domain \\
Rho filter & Restoring frequency spectrum \\
Velocity analysis & Loop as required \\
NMO & \\
Residual static correction & \\
Stacking & \\
Despiking & \\
Optional AGC & 100 ms window length \\
Migration & Stolt migration for best sediment structure or FD migration for amplitude preservation \\
Optional AGC & 100 ms window length \\
\hline
\end{tabular}

Notes: Canadian Oceanographical Acoustic Measurement System data from Cruise PGC9902. Alternative bandpass filters were applied dependent on target reflectors. For amplitude preservation, finite-difference (FD) migration was preferred over Stolt migration and automatic gain control $(A G C)$ was not applied. $A E L=$ array element localization, $B S R=$ bottom-simulating reflector, $\mathrm{NMO}=$ normal moveout. 